\title{
Chiral Alkyl Groups at Position 3(1') of Pyropheophorbide a Specify Uptake and Retention by Tumor Cells and are Essential for Effective Photodynamic Therapy
}
Ravindra R Cheruku ${ }^{1}$. Erin C. Tracy ${ }^{2}$, Walter Tabaczynski ${ }^{1}$, Joseph R Missert ${ }^{1}$, Heinz Baumann ${ }^{2^{\star}}$, and Ravindra K Pandey ${ }^{1^{*}}$

${ }^{1}$ PDT Center and Department of Cell Stress Biology and ${ }^{2}$ Department of Molecular and Cellular Biology, Roswell Park Comprehensive Cancer Center, Buffalo, NY 14263

\section{Table of Contents:}

- Figure S1: ${ }^{1} \mathrm{H}$ NMR spectrum of Compound 1

Page S4

- Figure S2: ${ }^{13} \mathrm{C}$ NMR spectrum of Compound 1

Page S5

- Figure S3: ${ }^{1}$ H NMR spectrum of Compound 2

Page 56

- Figure S4: ${ }^{13} \mathrm{C}$ NMR spectrum of Compound 2

Page 57

- Figure S5: ${ }^{1} \mathrm{H}$ NMR spectrum of Compound 3

Page S8

- Figure S6: ${ }^{13} \mathrm{C}$ NMR spectrum of Compound 3

Page S9

- Figure S7: ${ }^{1 H}$ NMR spectrum of Compound 4

Page $\$ 10$

- Figure S8: ${ }^{13} \mathrm{C}$ NMR spectrum of Compound 4

Page S11

- Figure S9: ${ }^{1} \mathrm{H}$ NMR spectrum of Compound 5

Page S12

- Figure S10: ${ }^{13} \mathrm{C}$ NMR spectrum of Compound 5

Page S13

- Figure S11: ${ }^{1} \mathrm{H}$ NMR spectrum of Compound 6

Page S14

- Figure S12: ${ }^{13} \mathrm{C}$ NMR spectrum of Compound 6

Page S15

- Figure S13: ${ }^{1} \mathrm{H}$ NMR spectrum of Compound 7

Page $\$ 16$

- Figure S14: ${ }^{13} \mathrm{C}$ NMR spectrum of Compound 7

Page $\mathrm{S} 17$

- Figure S15: ${ }^{1} \mathrm{H}$ NMR spectrum of Compound 8

Page S18

- Figure S16: ${ }^{13} \mathrm{C}$ NMR spectrum of Compound 8 
- Figure S17: 'H NMR spectrum of Compound 9

- Figure S18: ${ }^{13} \mathrm{C}$ NMR spectrum of Compound 9

- Figure S19: ${ }^{1} \mathrm{H}$ NMR spectrum of Compound 10

- Figure S20: ${ }^{13} \mathrm{C}$ NMR spectrum of Compound 10

- Figure S21: 'H NMR spectrum of Compound 11

- Figure S22: ${ }^{13} \mathrm{C}$ NMR spectrum of Compound 11

- Figure S23: 'H NMR spectrum of Compound 13

- Figure S24: ${ }^{13} \mathrm{C}$ NMR spectrum of Compound 13

- Figure S25: ${ }^{1} \mathrm{H}$ NMR spectrum of Compound 15

- Figure S26: ${ }^{13} \mathrm{C}$ NMR spectrum of Compound 15

- Figure S27: 'H NMR spectrum of Compound $\mathbf{1 6}$

- Figure S28: ${ }^{13} \mathrm{C}$ NMR spectrum of Compound 16

- Figure S29: ${ }^{1} H$ NMR spectrum of Compound 20

- Figure S30: ${ }^{13} \mathrm{C}$ NMR spectrum of Compound 20

- Figure S31:; H NMR spectrum of Compound 23

- Figure S32: ${ }^{1} \mathrm{H}$ NMR spectrum of Compounds 24 \& 24a

- Figure S33: ${ }^{13} \mathrm{C}$ NMR spectrum of Compounds 24 \&24a

- Figure S34:
Page S20

Page S21

Page S22

Page S23

Page S24

Page S25

Page S26

Page S27

Page S28

Page 529

Page S30

Page S31

Page S32

Page S33

Page S34

Page S35

Page $\$ 36$

Page S37

Confluent monolayers of HNT1 cells (passage 116, low retaining activity for HPPH) were incubated either for $30 \mathrm{~min}$ at $37^{\circ} \mathrm{C}$ in serum-free DMEM containing $1.6 \mu \mathrm{M}$ of HPPH or PS4 or $5 \mathrm{~h}$ at $37^{\circ} \mathrm{C}$ in DMEM containing $10 \% \mathrm{FBS}$ and $1.6 \mu \mathrm{M}$ of the same PSs. After imaging the cultures for the cellular level of PSs at 100X magnification, the cells were continued incubated for $15 \mathrm{~h}$ in DMEM containing 10\% FBS (Chase) to determine PS retention based on detection of the PS's fluorescence.

- Figure S35:

Page S38

Comparison of HPPH with PS-6 to determine the effect of the chiral methyl group at position $3\left(1^{\prime}\right)$. Confluent monolayers of HNT1 cells (passage 28 , high retaining activity for HPPH) treated with 1.6 $\mu \mathrm{M}$ of the indicated PSs and cellular level of PSs imaged by fluorescent microscopy at $100 \mathrm{X}$ magnification using $1 \mathrm{sec}$ camera exposure for each culture and timepoint. 
- Figure S36:

Page $\$ 39$

Testing the effect of chiral centers on the activity of methyl ester derivatives. Confluent monolayers of TEC-1-2 cells (passage 74) were treated for $30 \mathrm{~min}$ on ice with serum-free DMEM containing $1.6 \mu \mathrm{M}$ PSs or for $4 \mathrm{~h}$ at $37^{\circ} \mathrm{C}$ with DMEM containing $10 \% \mathrm{FBS}$ and 1.6 $\mu M$ PSs. Cellular retention of the PSs was imaged at $100 \mathrm{X}$ magnification followed by $18 \mathrm{~h}$ and $48 \mathrm{~h}$ chase periods.

- Figure S37:

Page S40

Cellular retention of carboxylated PSs by tumor cells with low retention of HPPH. Confluent monolayers of HN-174 T-EC (passage 7) were incubated with RPMI containing $10 \%$ FBS and $1.6 \mu \mathrm{M}$ PSs as indicated. Retention of the PSs were imaged after 24 and $48 \mathrm{~h}$ chase periods.

- Figure S38:

Page S41

Subcellular location of the PSs after $24 \mathrm{~h}$ chase period. The cultures of HN-174 T-EC (passage 7) used in Figure S37 after 24-h chase period were imaged by fluorescent microscopy at $400 \mathrm{X}$ magnification.

- Figure $\$ 39$

Page S42

Effect of alkyl structures at position $3\left(1^{\prime}\right)$ on cell surface binding, uptake and retention. Confluent cultures of HNT1 cells (passage 97) were treated for $30 \mathrm{~min}$ on ice with serumfree DMEM containing $1.6 \mu \mathrm{M}$ PSs or for $24 \mathrm{~h}$ at $37^{\circ} \mathrm{C}$ with DMEM containing $10 \% \mathrm{FBS}$ and 1.6 $\mu \mathrm{M}$ PSs. Cellular levels of the PSs were imaged at $100 \mathrm{X}$ magnification.

- Table 1:

Page $\$ 43$

Long wavelength absorption, extinction coefficient values, fluorescence, log $\mathrm{P}$ values and HPLC retention times (RT) of pyropheophorbide-a analogs

- Table 2: Molecular Formula Strings

Page $\$ 44$

- HPLC profiles: New compounds investigated for biological efficacy Page S 45-S52 
Figure S1: ${ }^{1} \mathrm{HNMR}\left(\mathrm{CDCl}_{3}, 400 \mathrm{MHz}\right)$

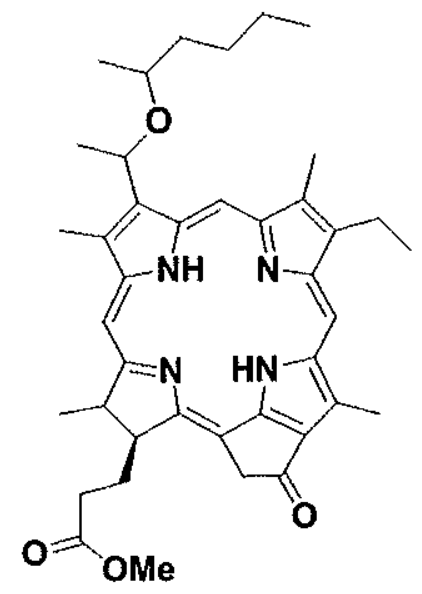

1

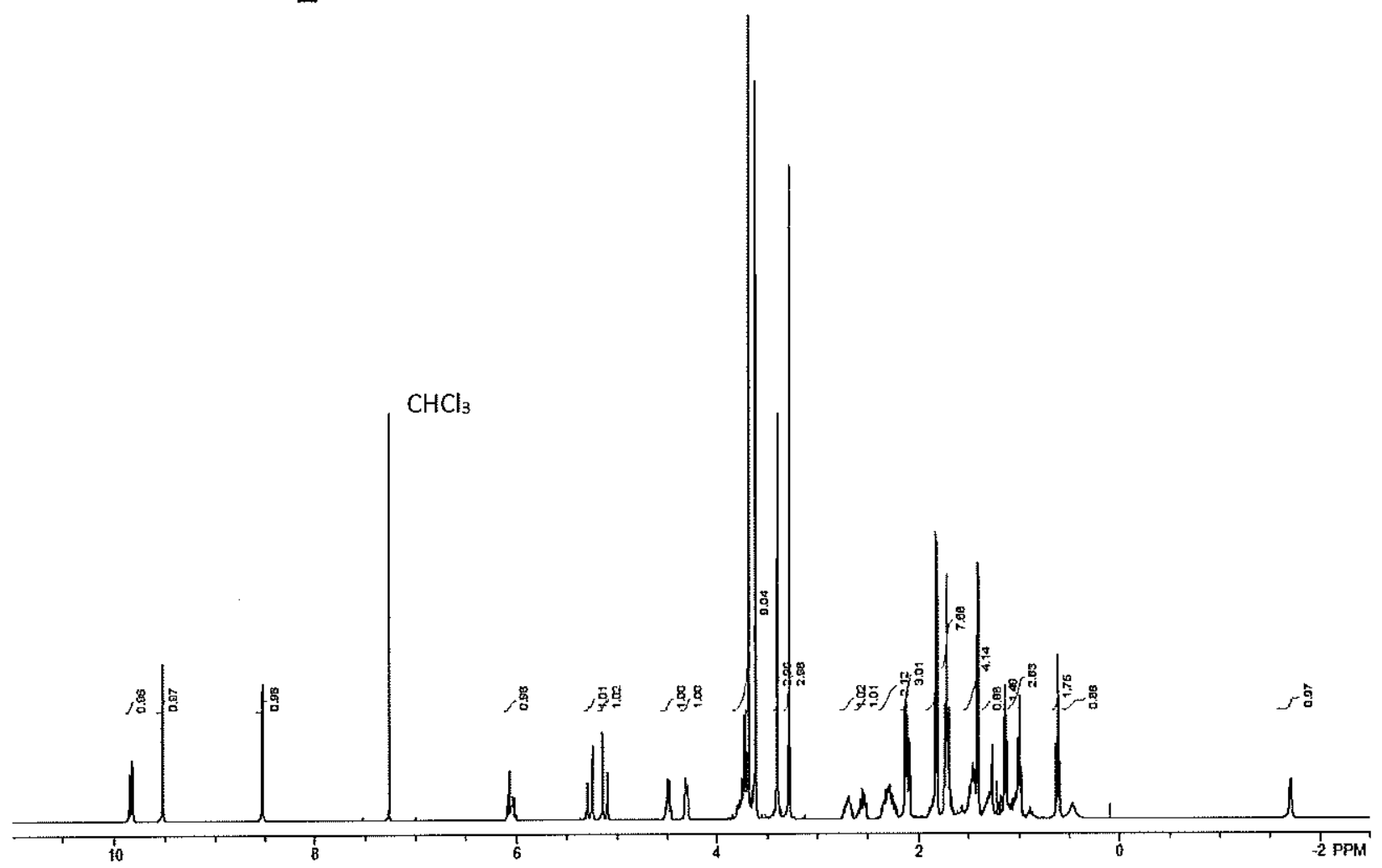


Figure $\mathrm{S} 2:{ }^{13} \mathrm{C} \mathrm{NMR}\left(\mathrm{CDCl}_{3}, 100 \mathrm{MHz}\right)$
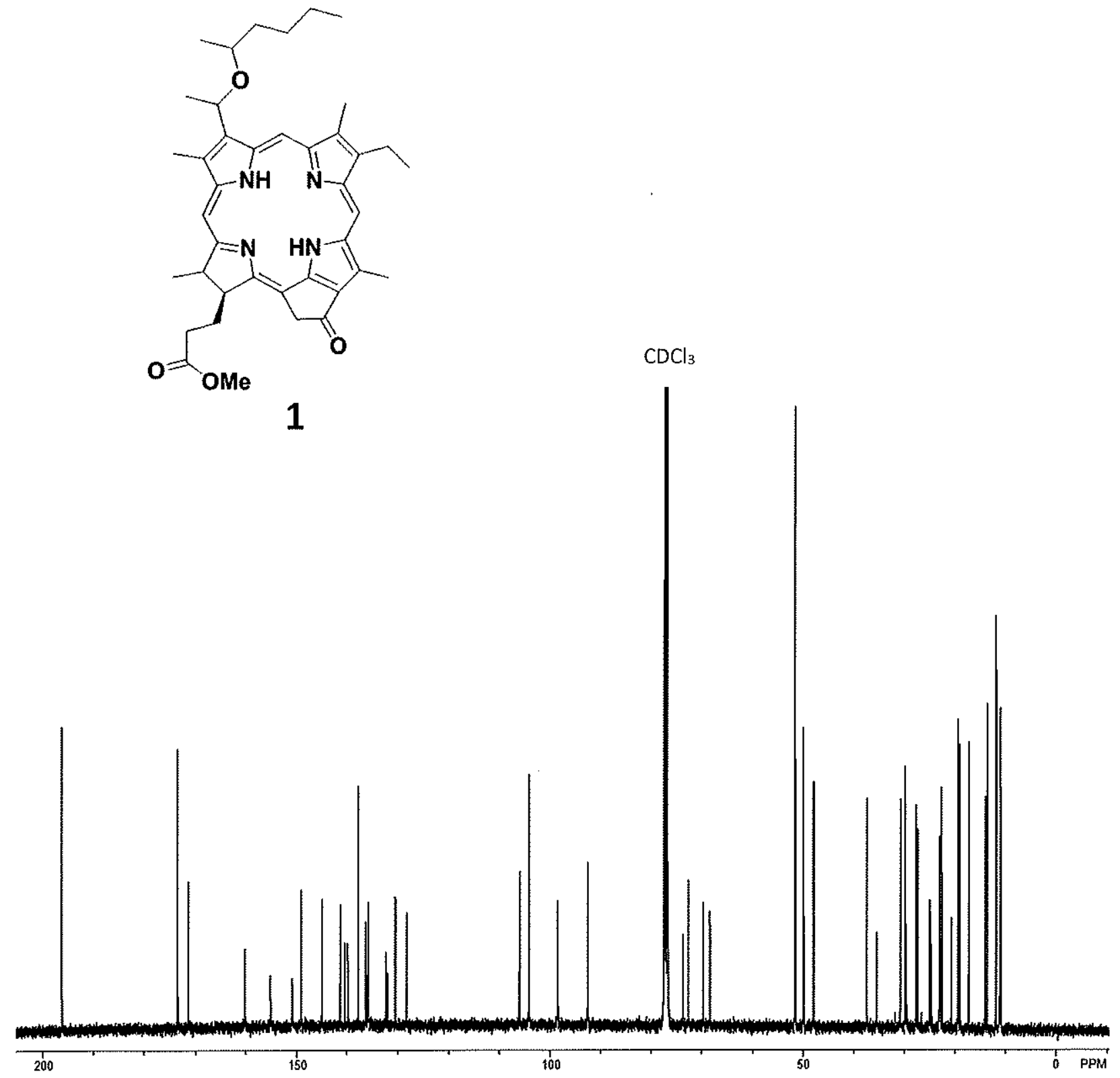
Figure S3: ${ }^{1} \mathrm{H}$ NMR (90:10 $\mathrm{CDCl}_{3} / \mathrm{CD}_{3} \mathrm{OD}, 400 \mathrm{MHz}$ )
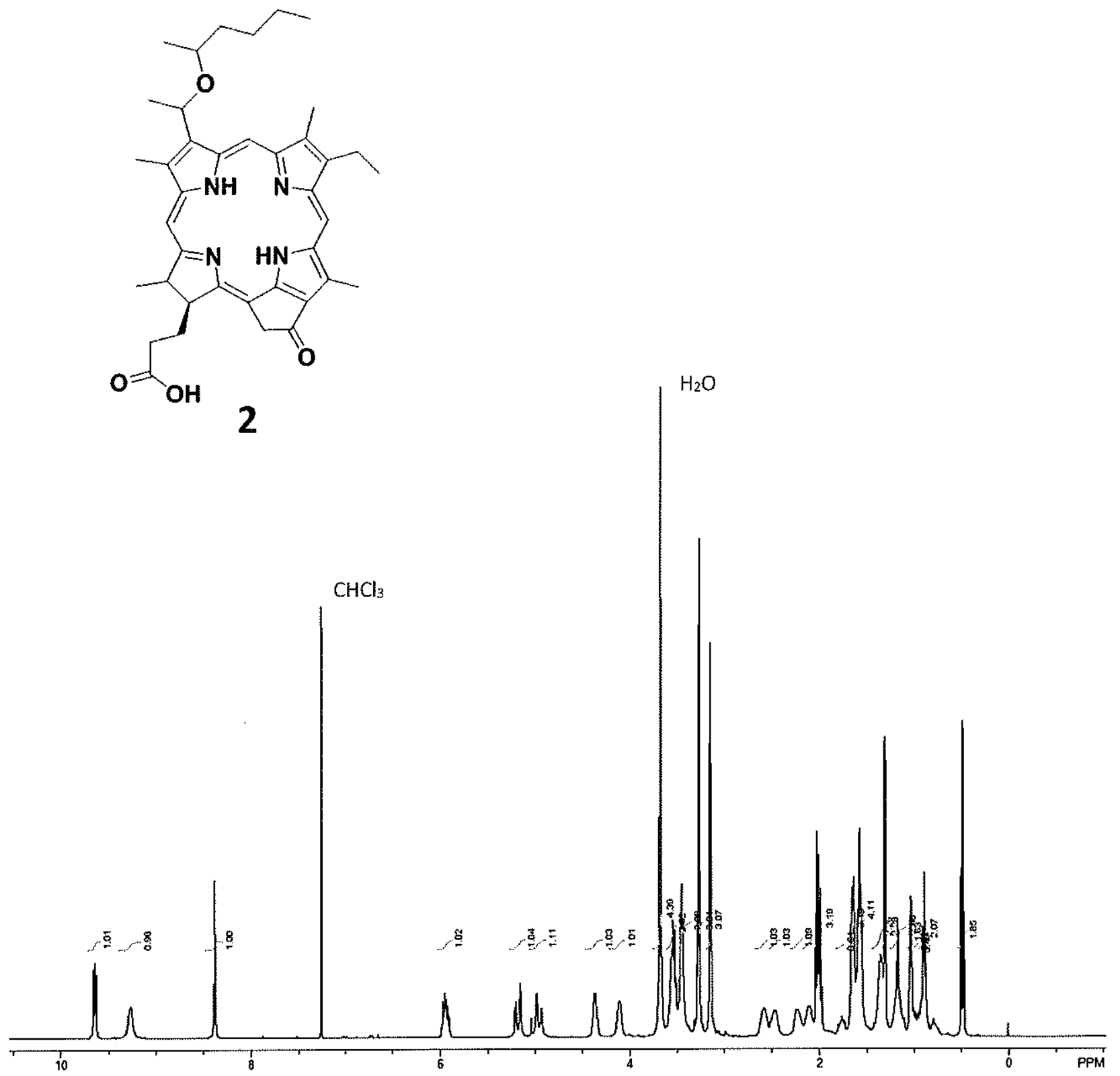
Figure S4: ${ }^{13} \mathrm{C}$ NMR (90:10 $\mathrm{CDCl}_{3} / \mathrm{CD}_{3} \mathrm{OD}, 100 \mathrm{MHz}$ )

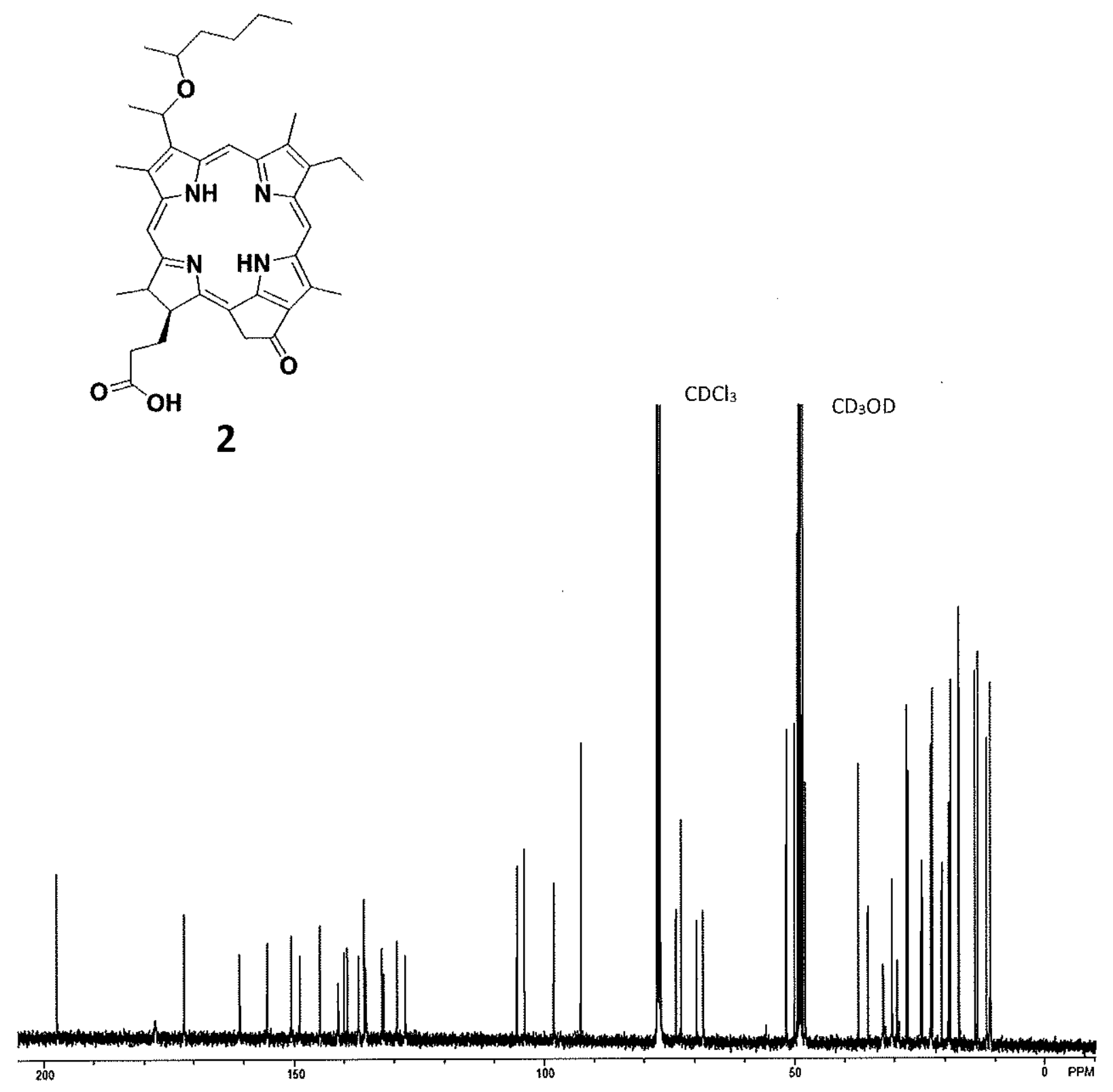


Figure S5: ${ }^{1} \mathrm{H} \mathrm{NMR}\left(\mathrm{CDCl}_{3}, 400 \mathrm{MHz}\right)$
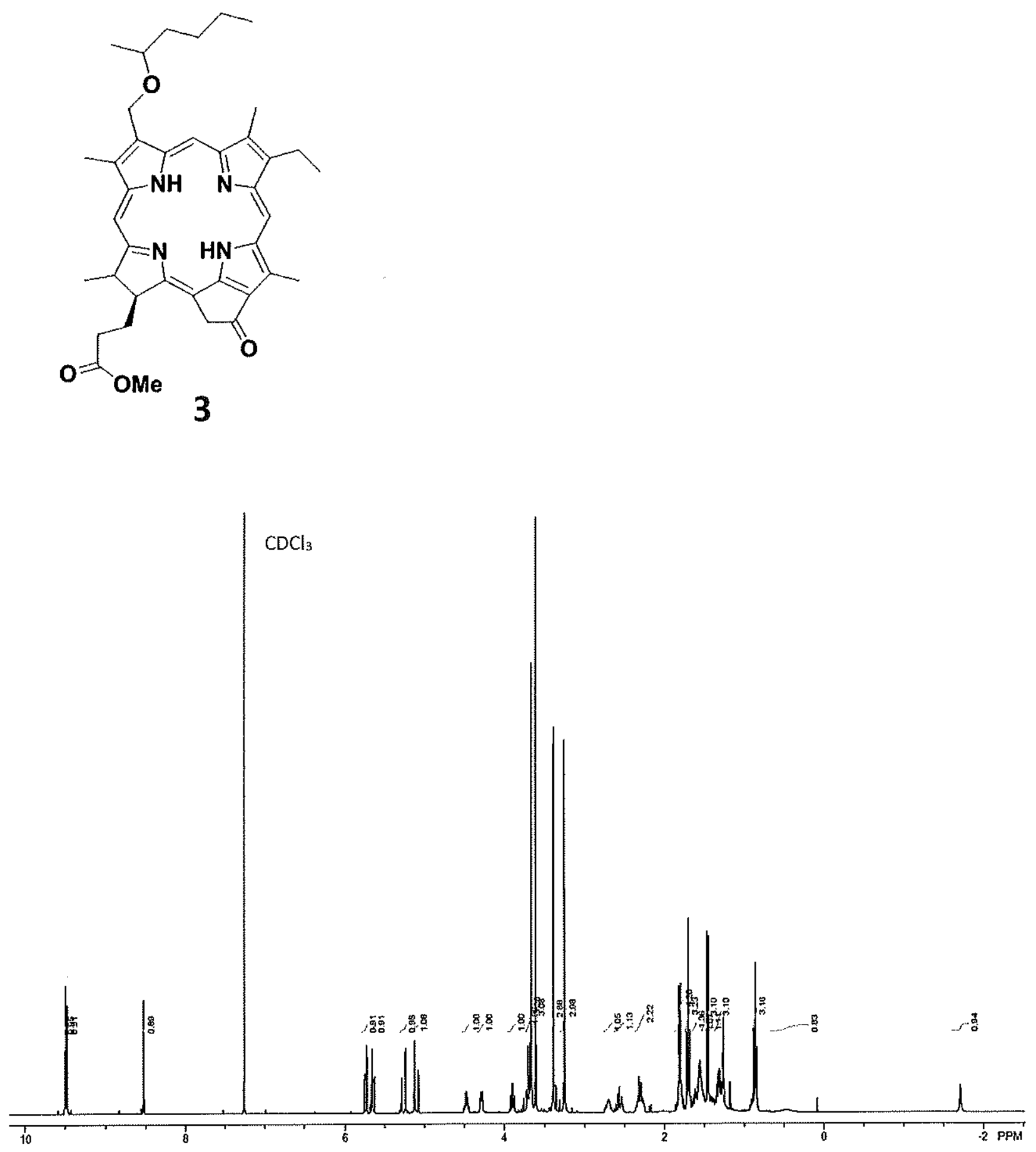
Figure S6: ${ }^{13} \mathrm{C} \mathrm{NMR}\left(\mathrm{CDCl}_{3}, 100 \mathrm{MHz}\right)$

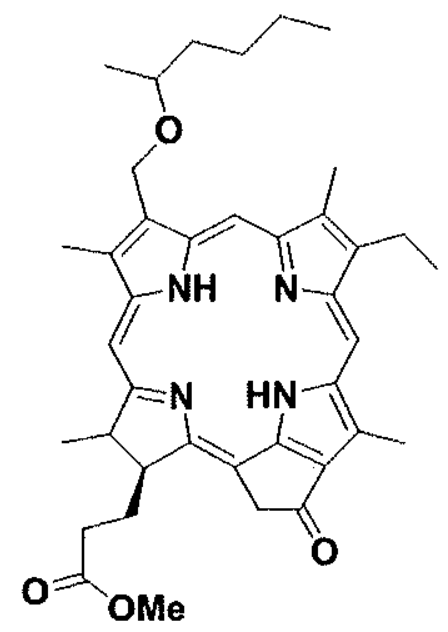

3

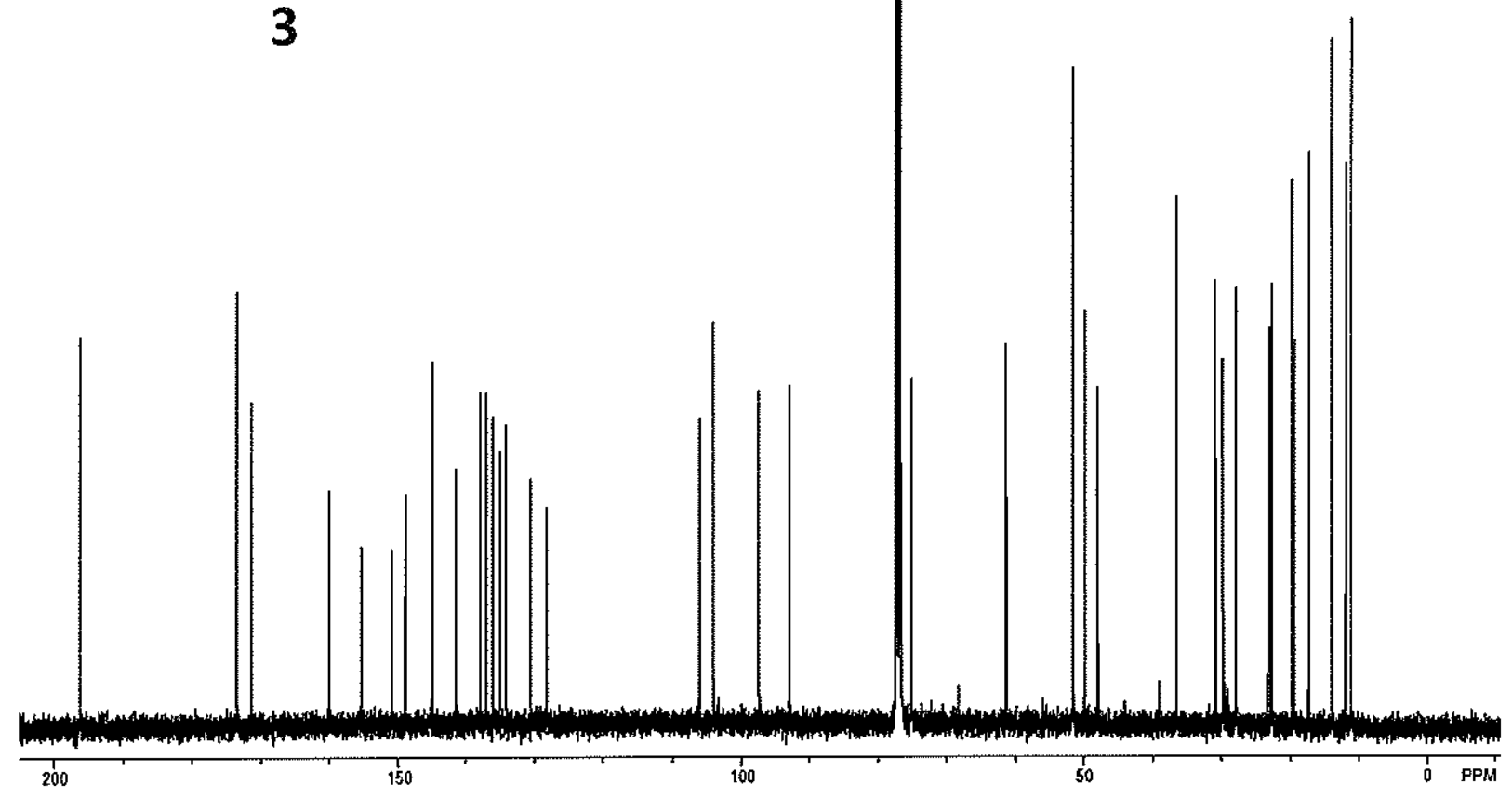


Figure S7: ${ }^{1} \mathrm{H} \mathrm{NMR}\left(\mathrm{CDCl}_{3}, 400 \mathrm{MHz}\right)$

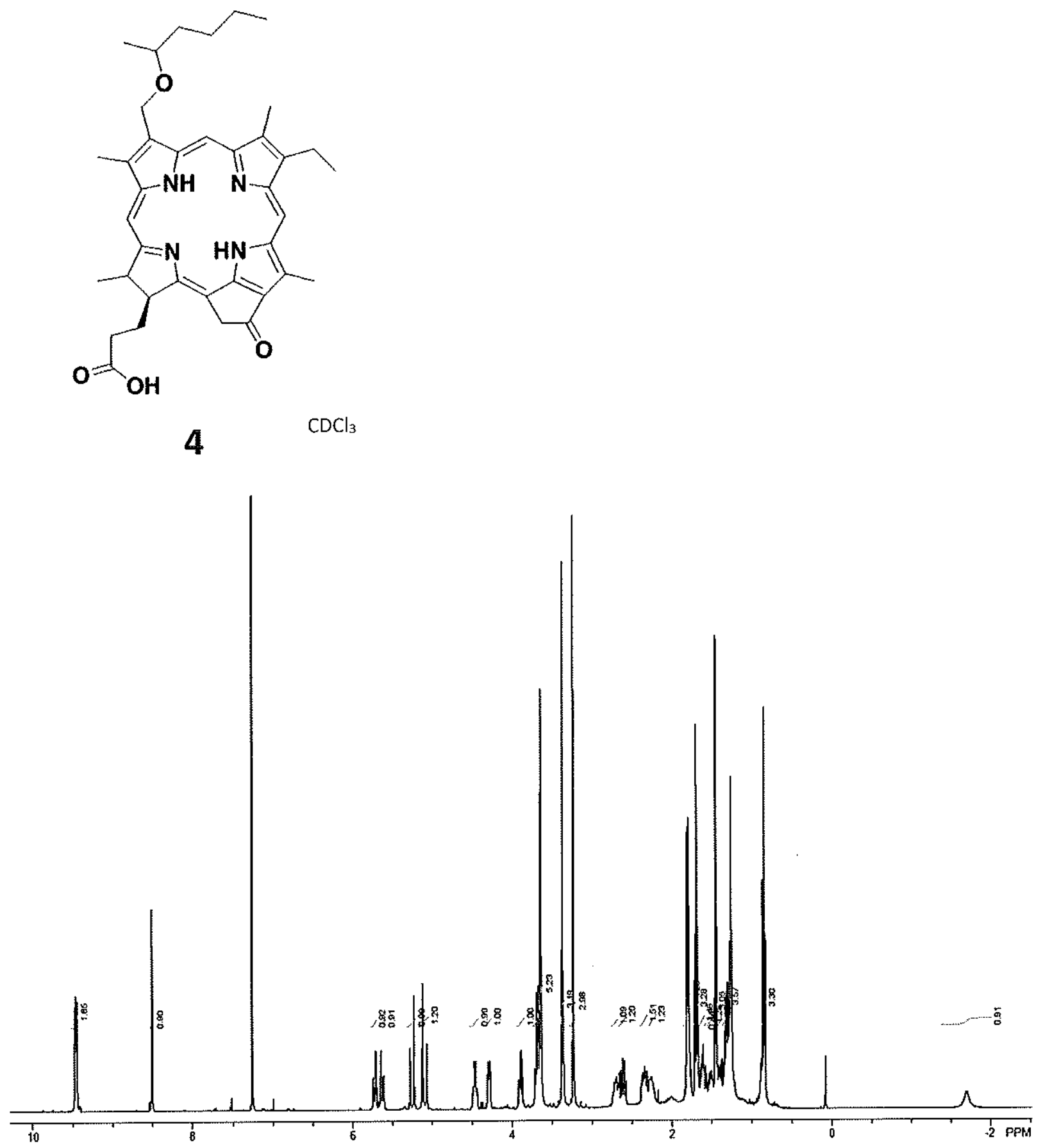


Figure S8: ${ }^{13} \mathrm{C} \mathrm{NMR}\left(\mathrm{CDCl}_{3}, 100 \mathrm{MHz}\right)$

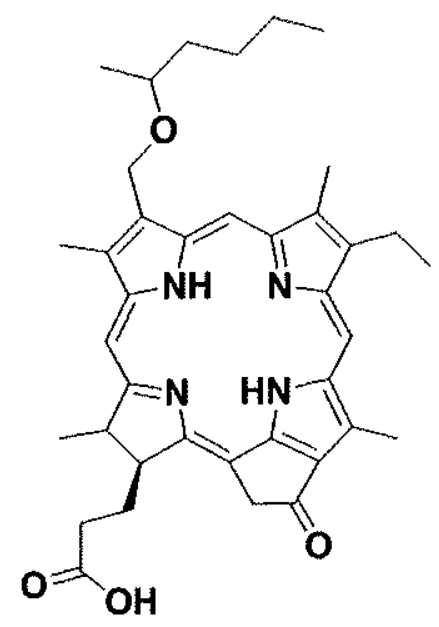

4

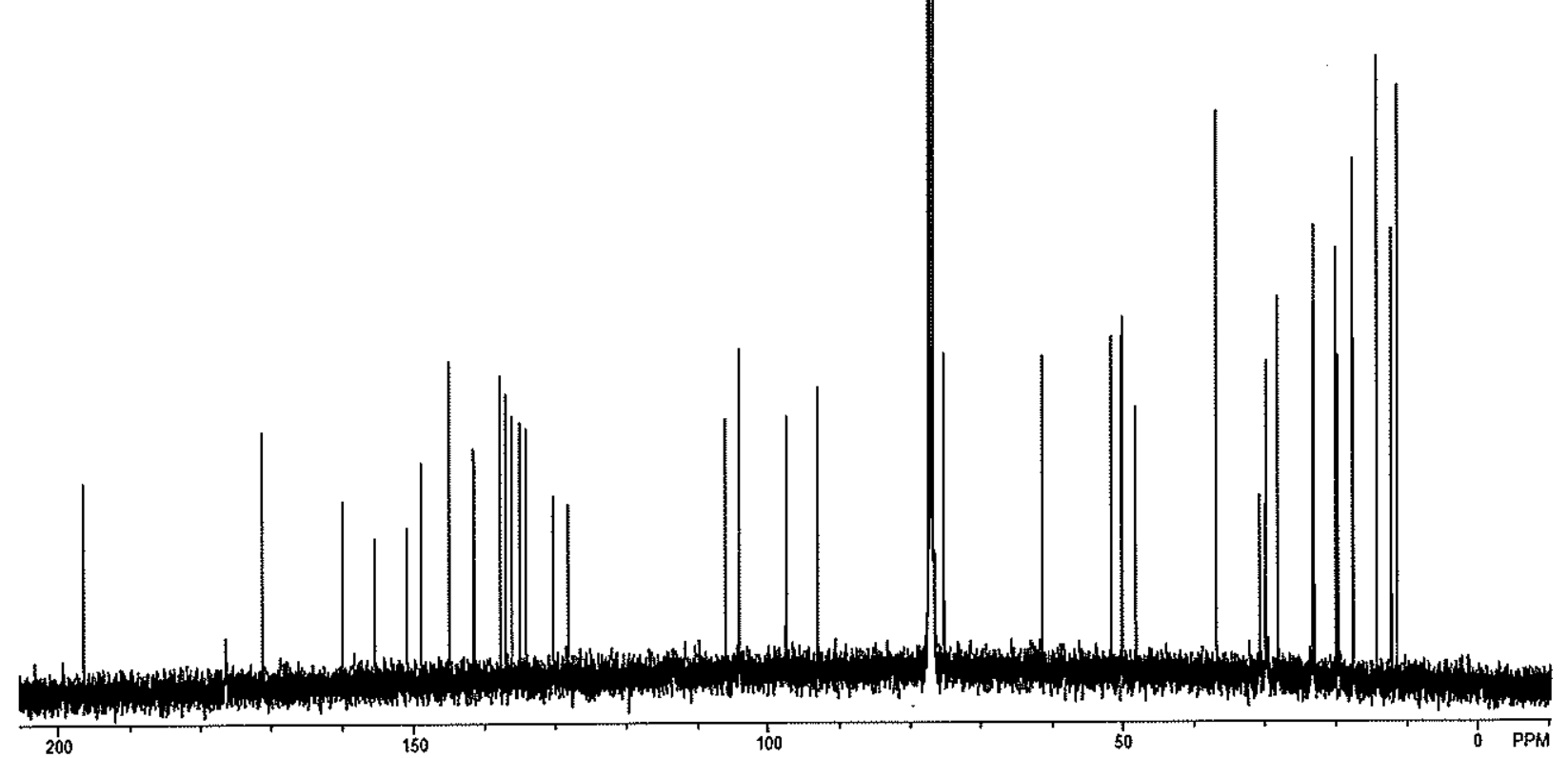


Figure S9: ${ }^{1} \mathrm{H} \mathrm{NMR}\left(\mathrm{CDCl}_{3}, 400 \mathrm{MHz}\right)$

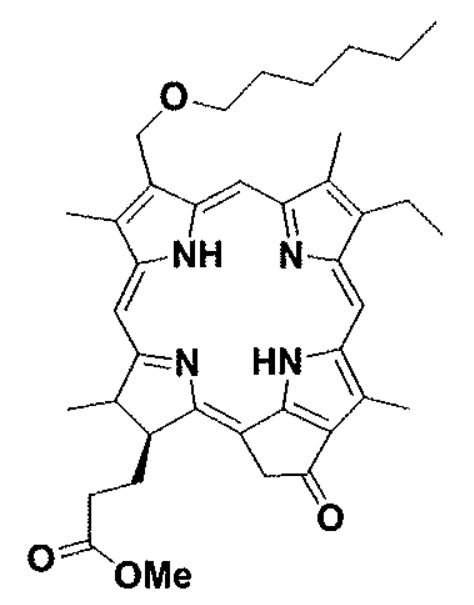

5

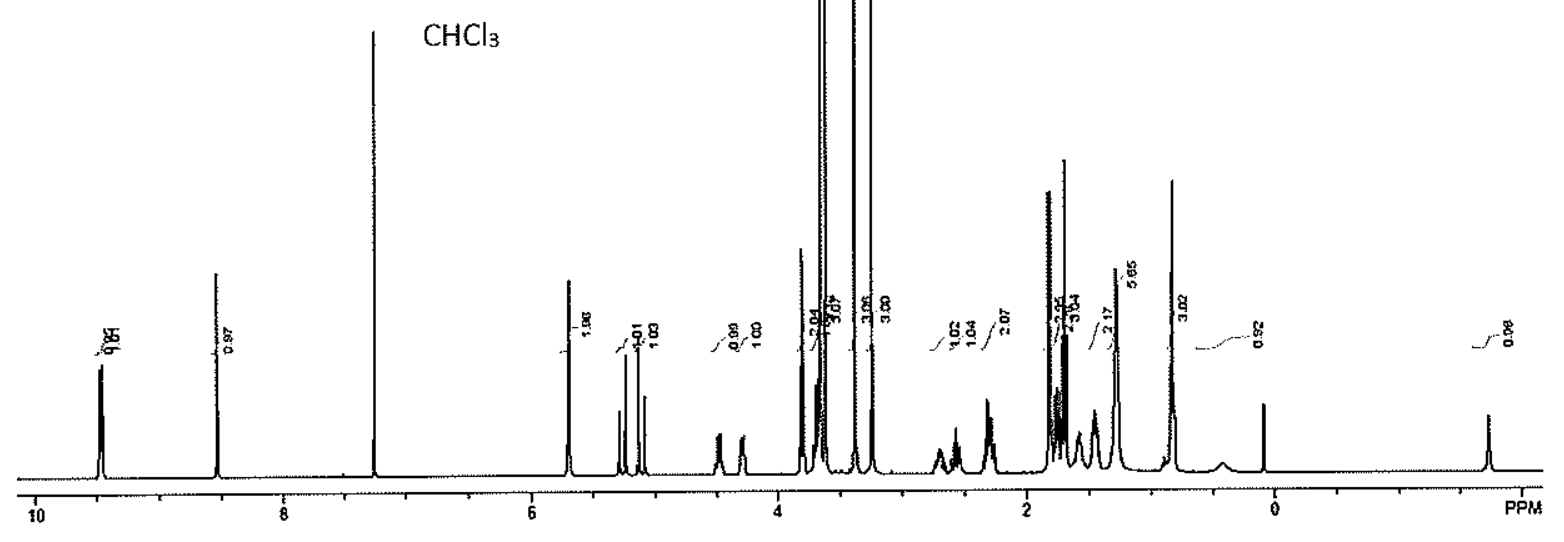


Figure S10: ${ }^{13} \mathrm{C} \mathrm{NMR}\left(\mathrm{CDCl}_{3}, 100 \mathrm{MHz}\right)$
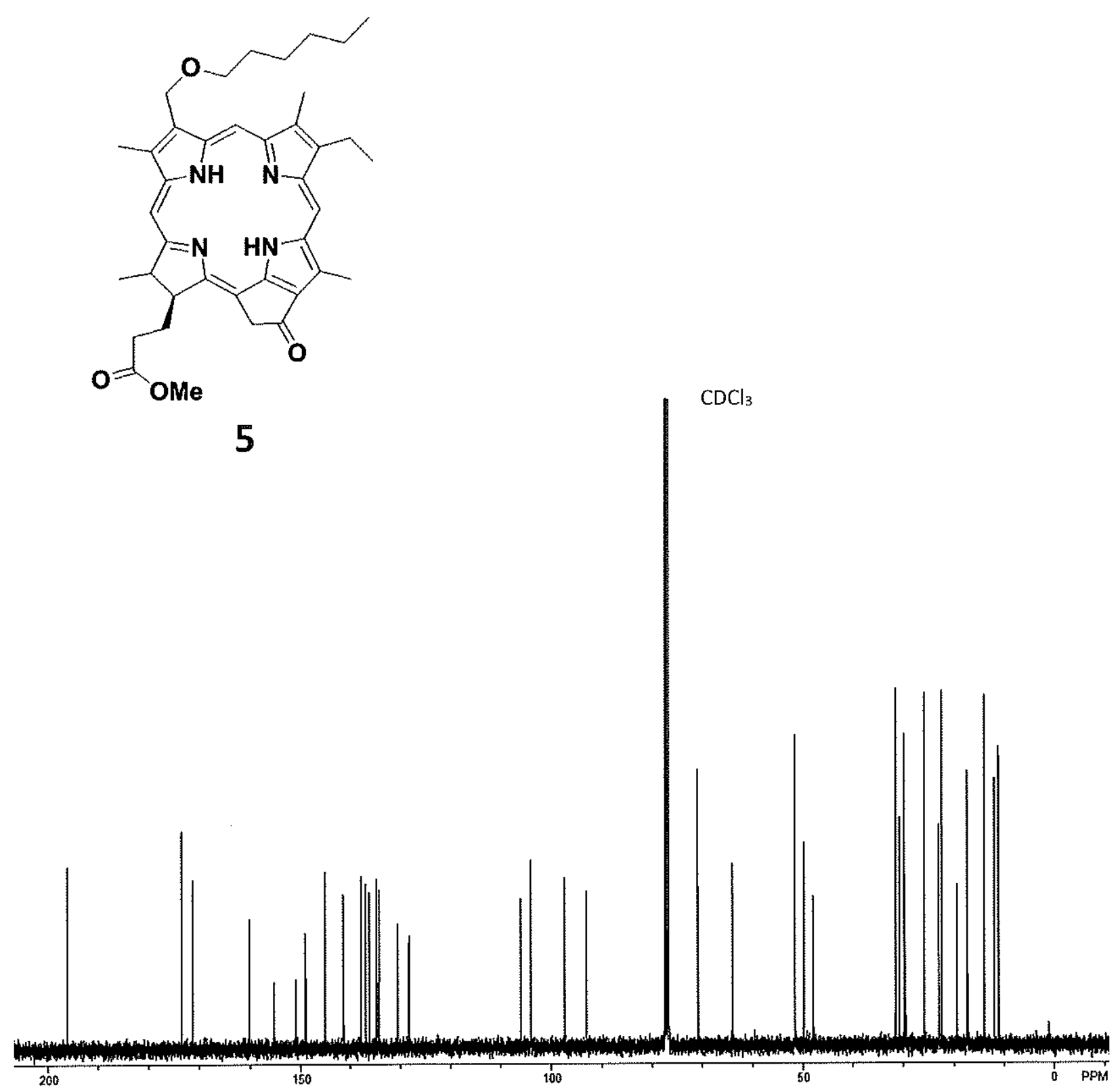
Figure S11: ${ }^{1} \mathrm{H} \mathrm{NMR}\left(\mathrm{CDCl}_{3}, 400 \mathrm{MHz}\right)$

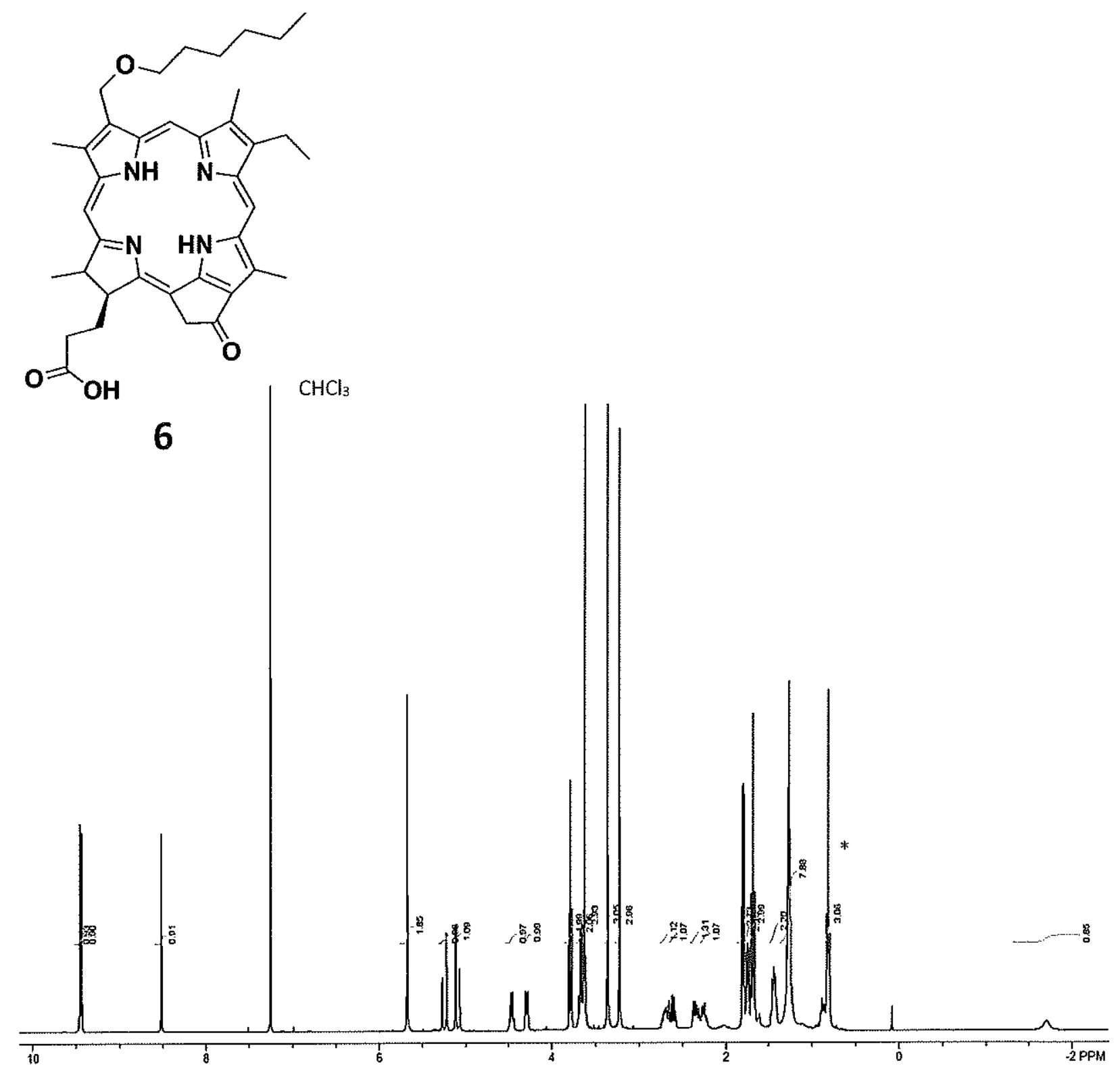


Figure S12: ${ }^{13} \mathrm{C} \mathrm{NMR}\left(\mathrm{CDCl}_{3}, 100 \mathrm{MHz}\right)$
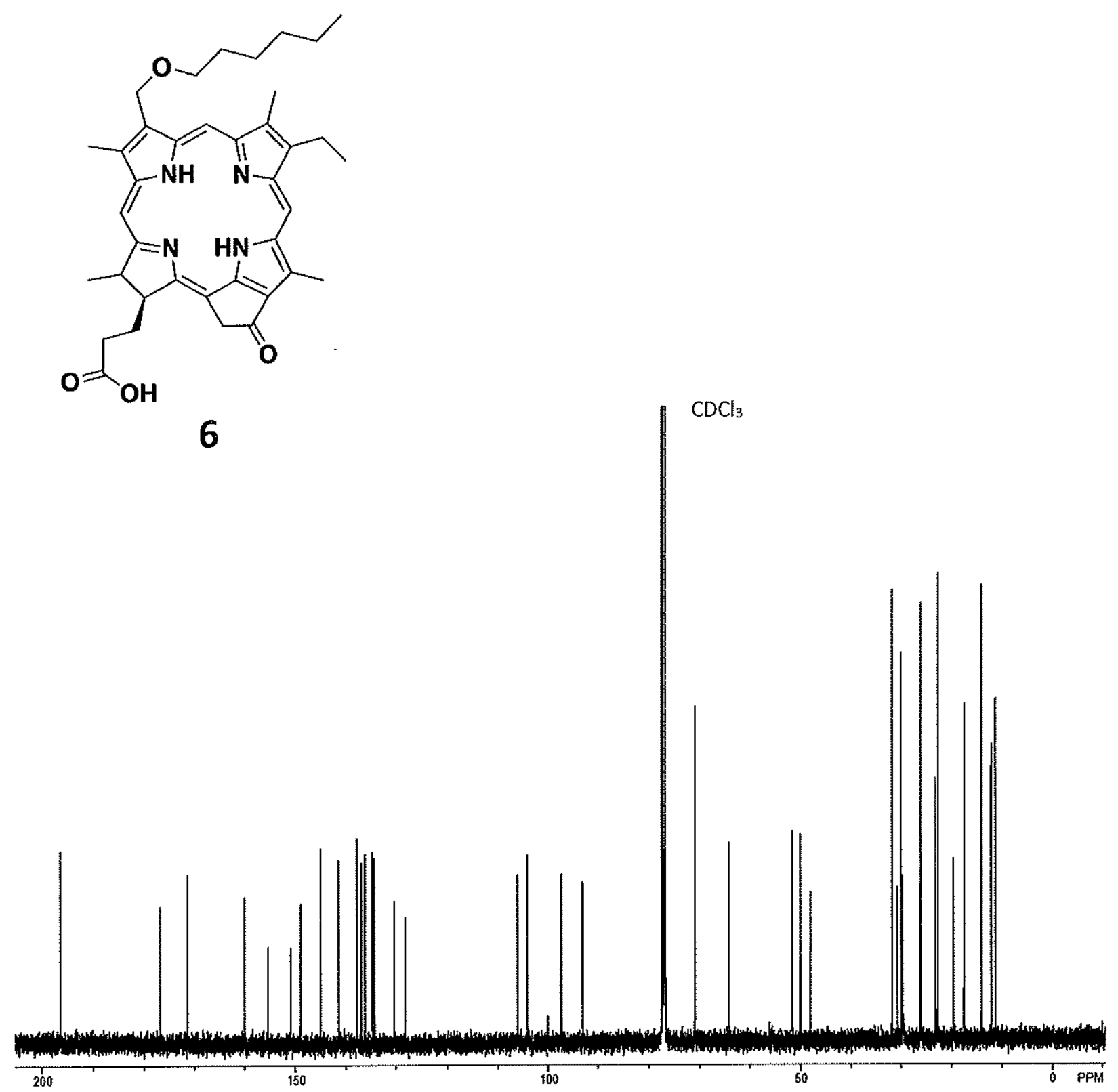
Figure S13: ${ }^{1} \mathrm{H} \mathrm{NMR}\left(\mathrm{CDCl}_{3}, 400 \mathrm{MHz}\right)$

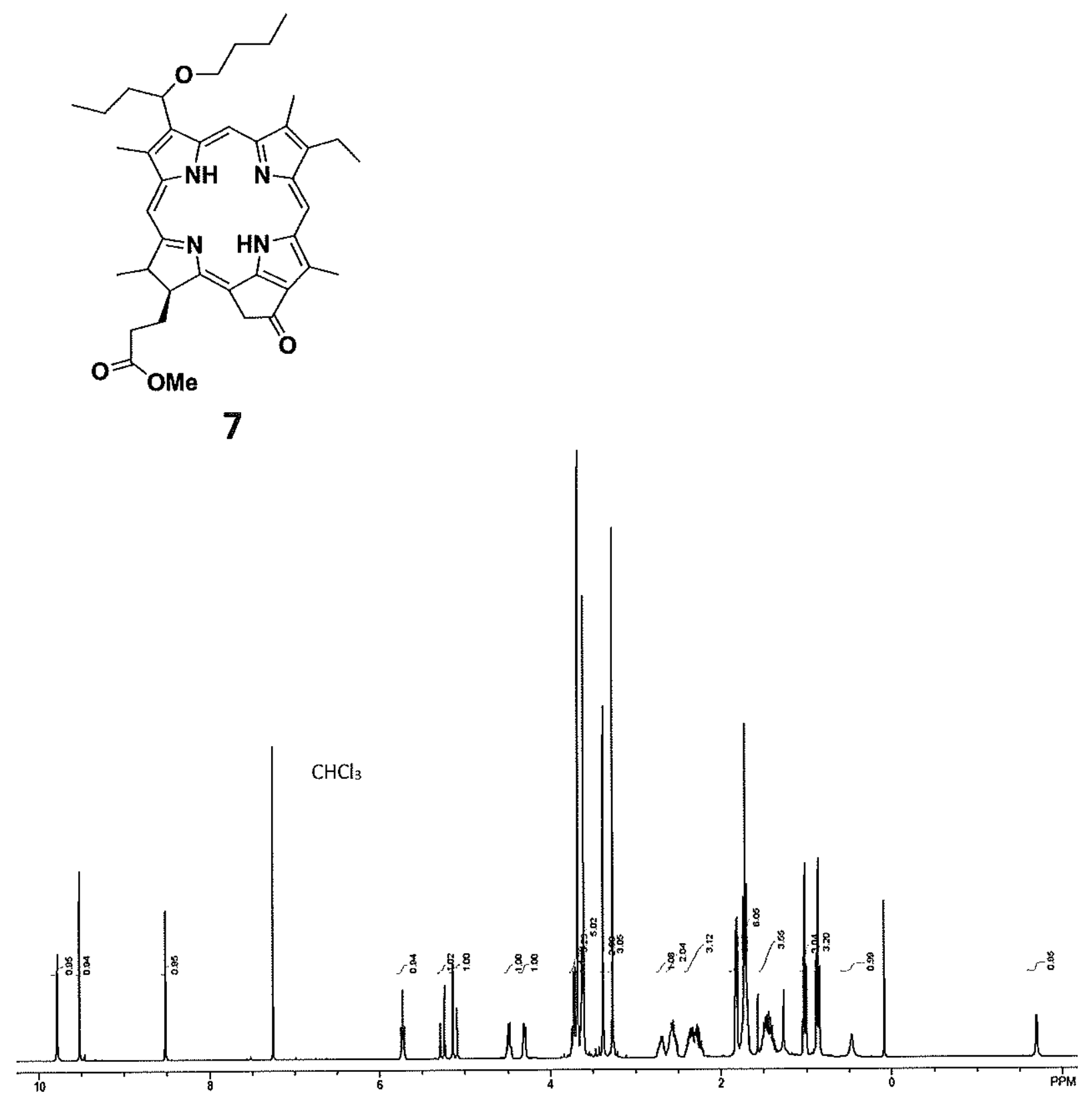


Figure S14: ${ }^{13} \mathrm{C}$ NMR $\left(\mathrm{CDCl}_{3}, 100 \mathrm{MHz}\right)$

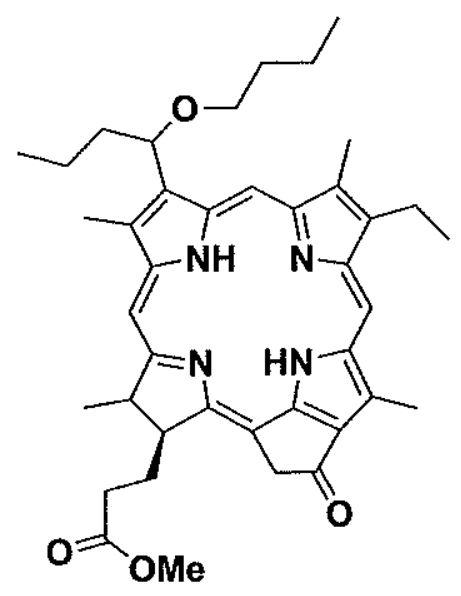

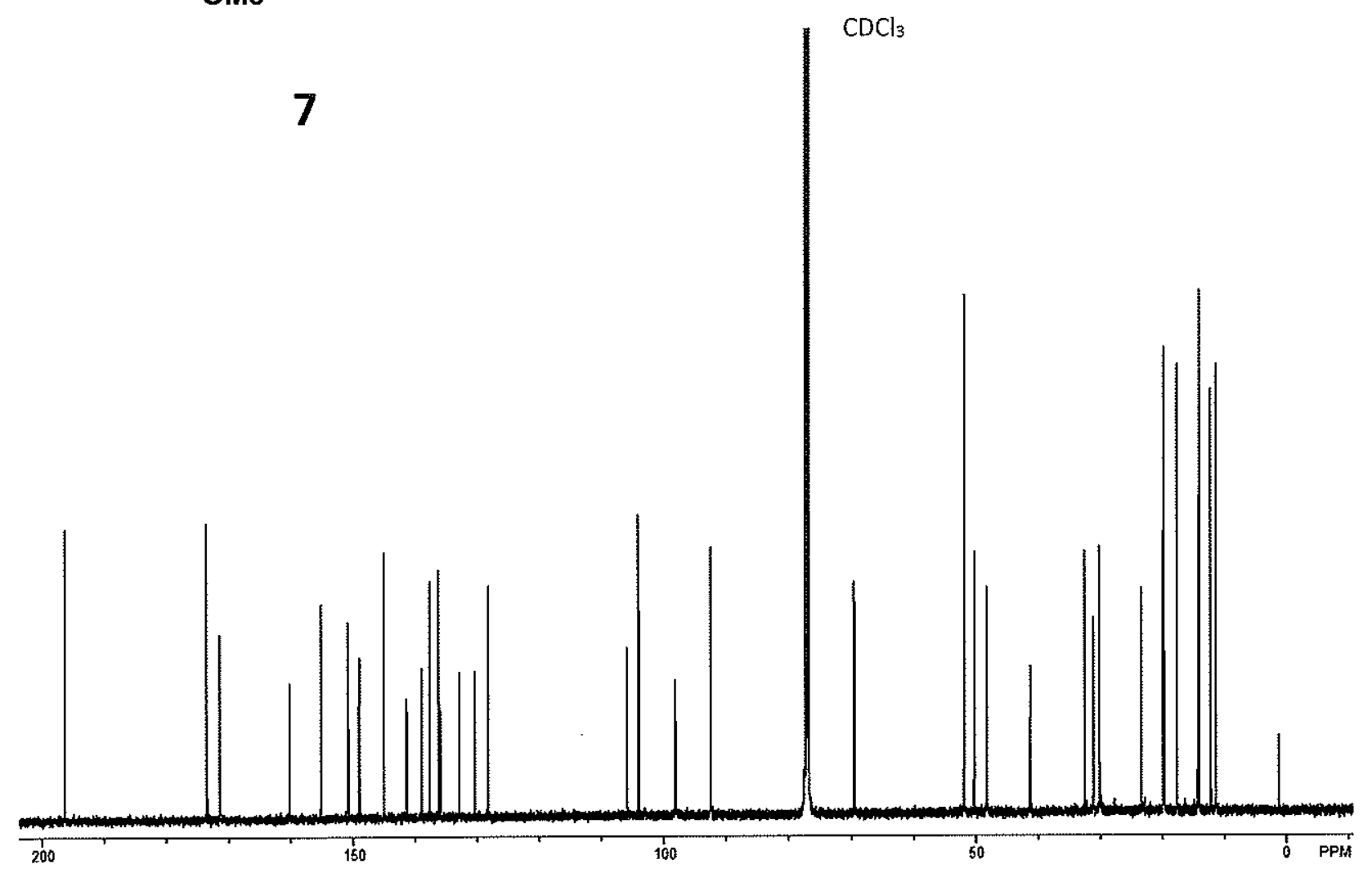


Figure S15: ${ }^{1} \mathrm{H}$ NMR (90:10 $\mathrm{CDCl}_{3} / \mathrm{CD}_{3} \mathrm{OD}, 400 \mathrm{MHz}$ )
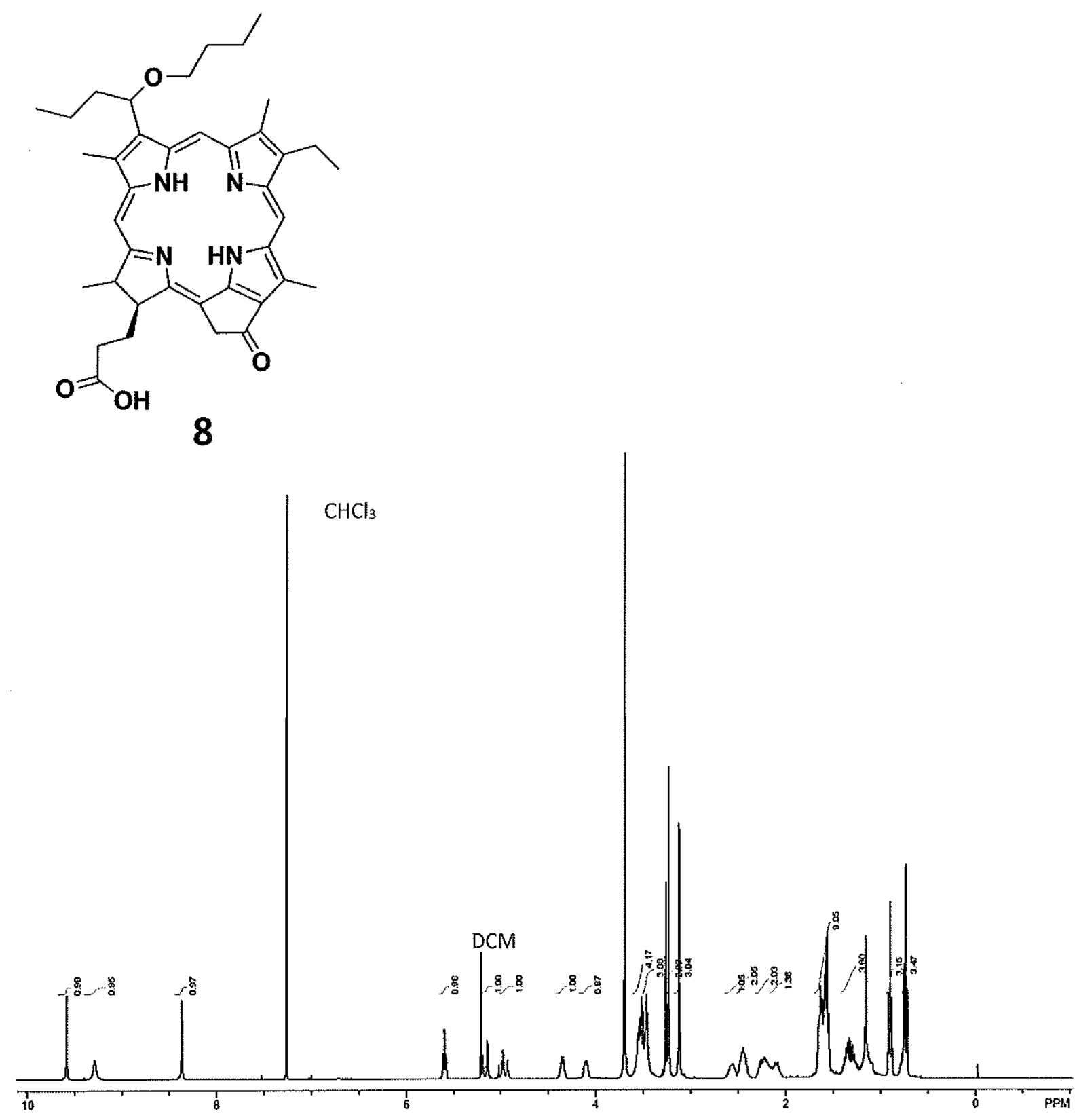
Figure S16: ${ }^{1} \mathrm{H}$ NMR (90:10 $\left.\mathrm{CDCl}_{3} / \mathrm{CD}_{3} \mathrm{OD}\right)$

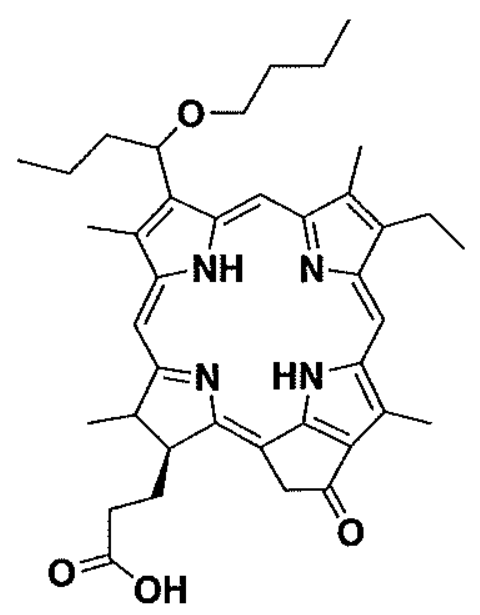

8

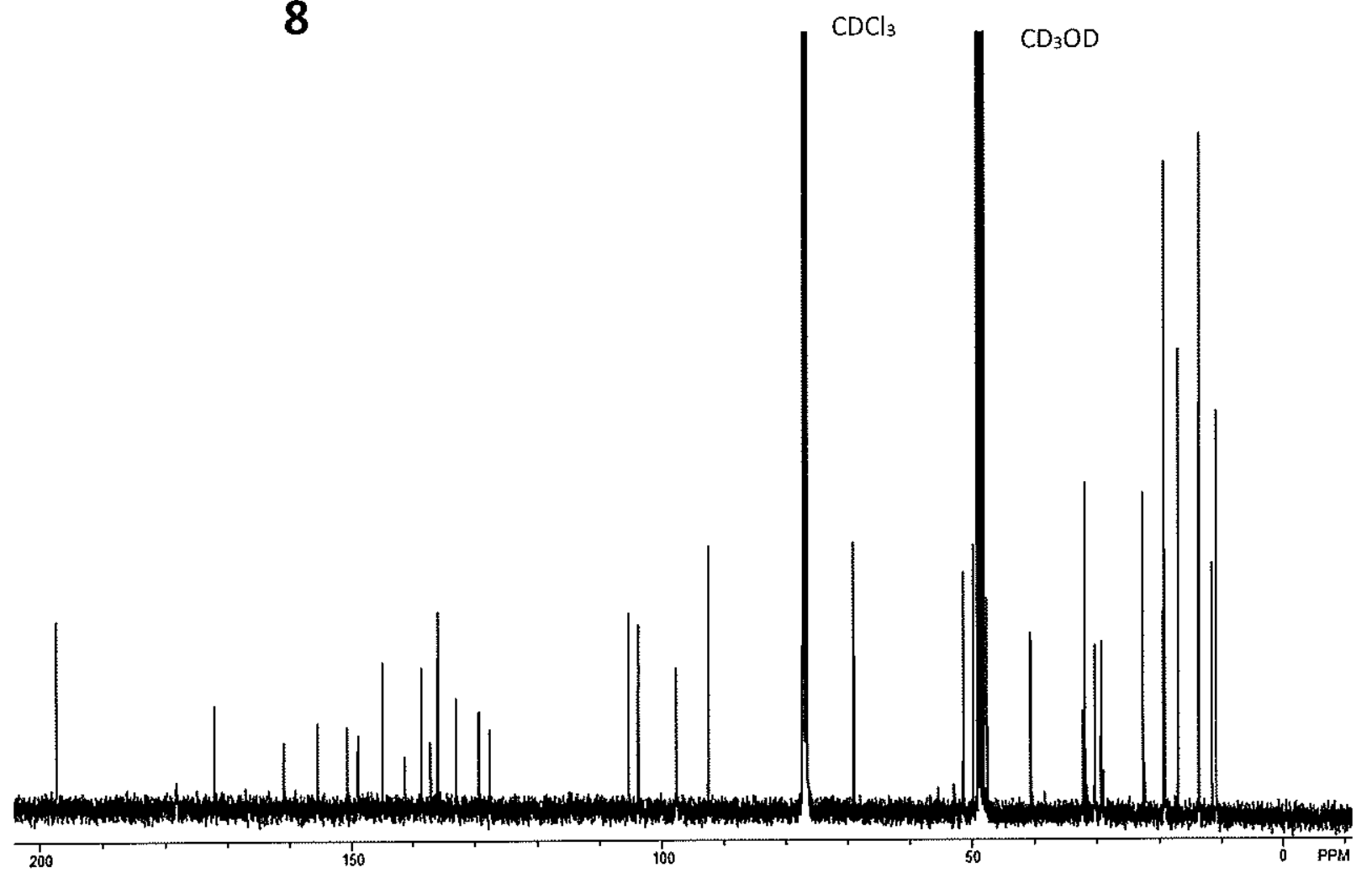


Figure S17: ${ }^{1} \mathrm{H} \mathrm{NMR}\left(\mathrm{CDCl}_{3}, 400 \mathrm{MHz}\right)$
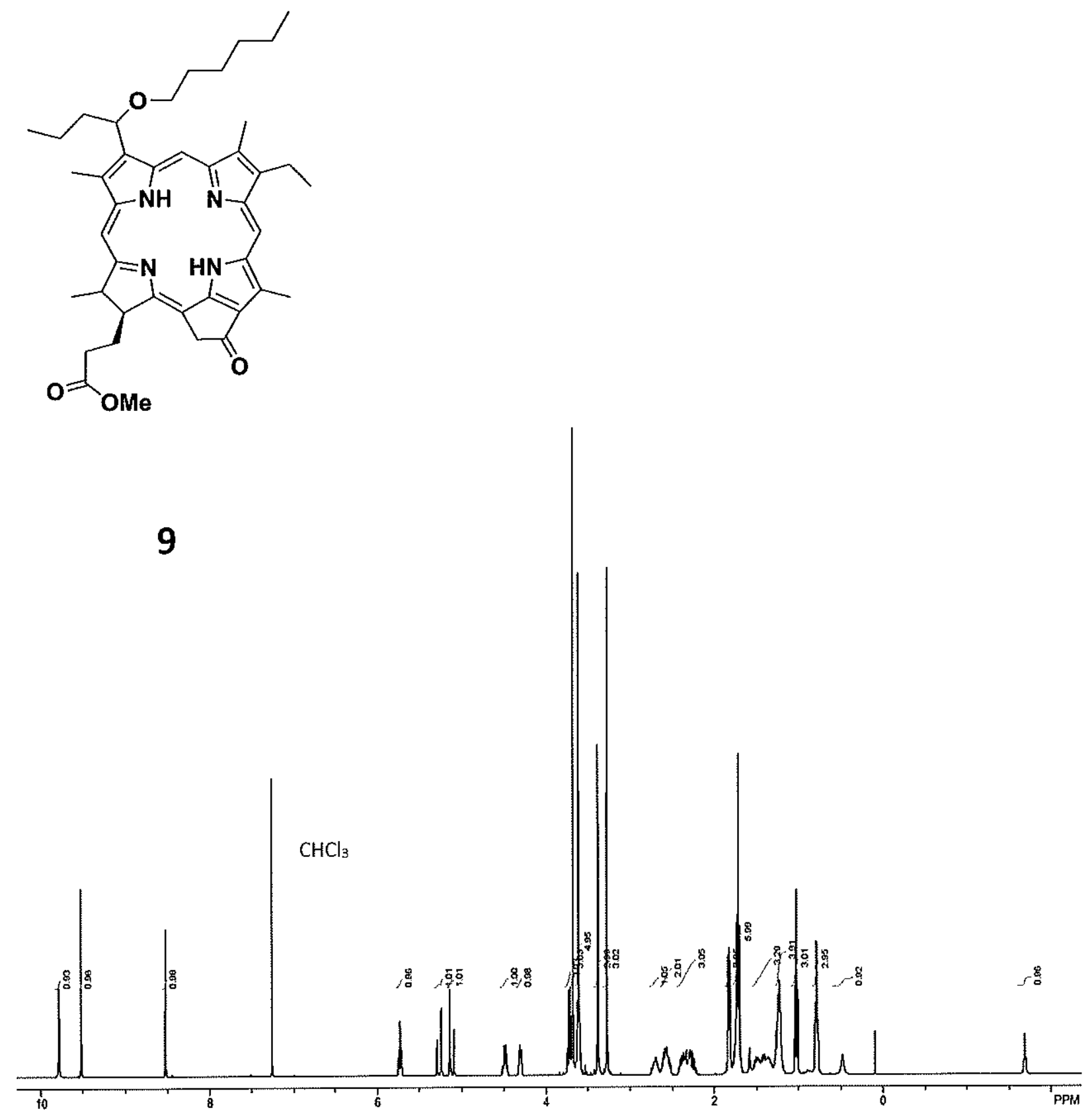
Figure S18: ${ }^{13} \mathrm{C} \mathrm{NMR}\left(\mathrm{CDCl}_{3}, 100 \mathrm{MHz}\right)$

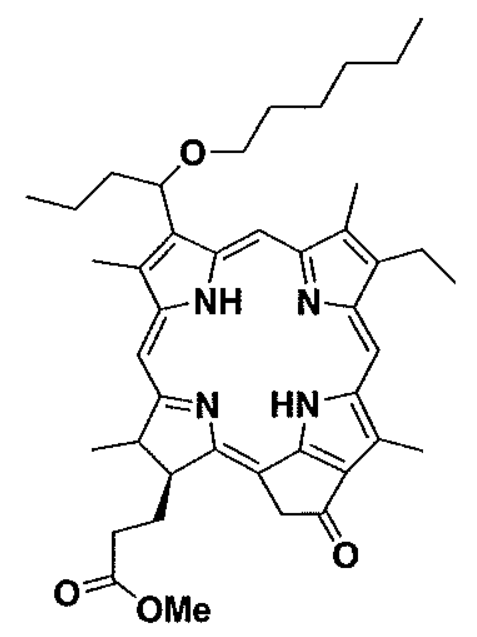

9

$\mathrm{CDCl}_{3}$

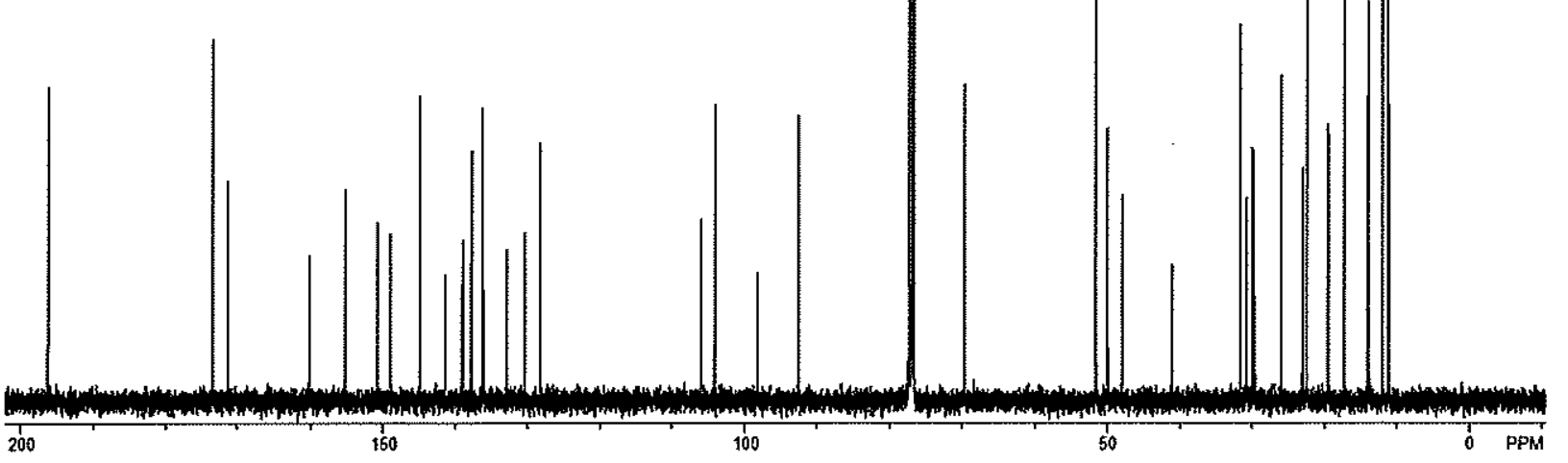


Figure S19: ${ }^{1} \mathrm{H}$ NMR (90:10 $\left.\mathrm{CDCl}_{3} / \mathrm{CD}_{3} \mathrm{OD}, 400 \mathrm{MHz}\right)$

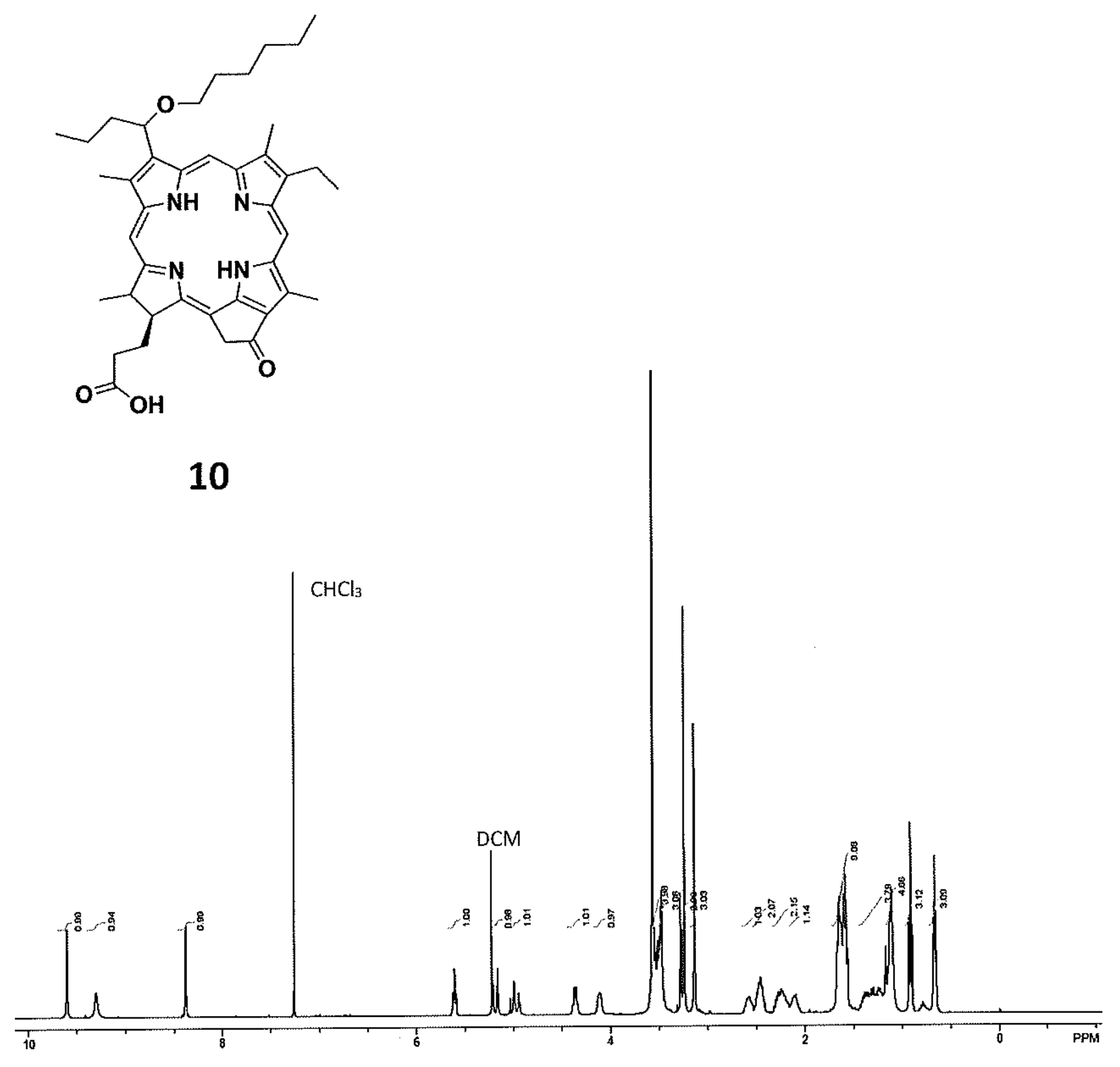


Figure S20: ${ }^{13} \mathrm{C}$ NMR (90:10 $\mathrm{CDCl}_{3} / \mathrm{CD}_{3} \mathrm{OD}, 100 \mathrm{MHz} \mathrm{MHz}$ )

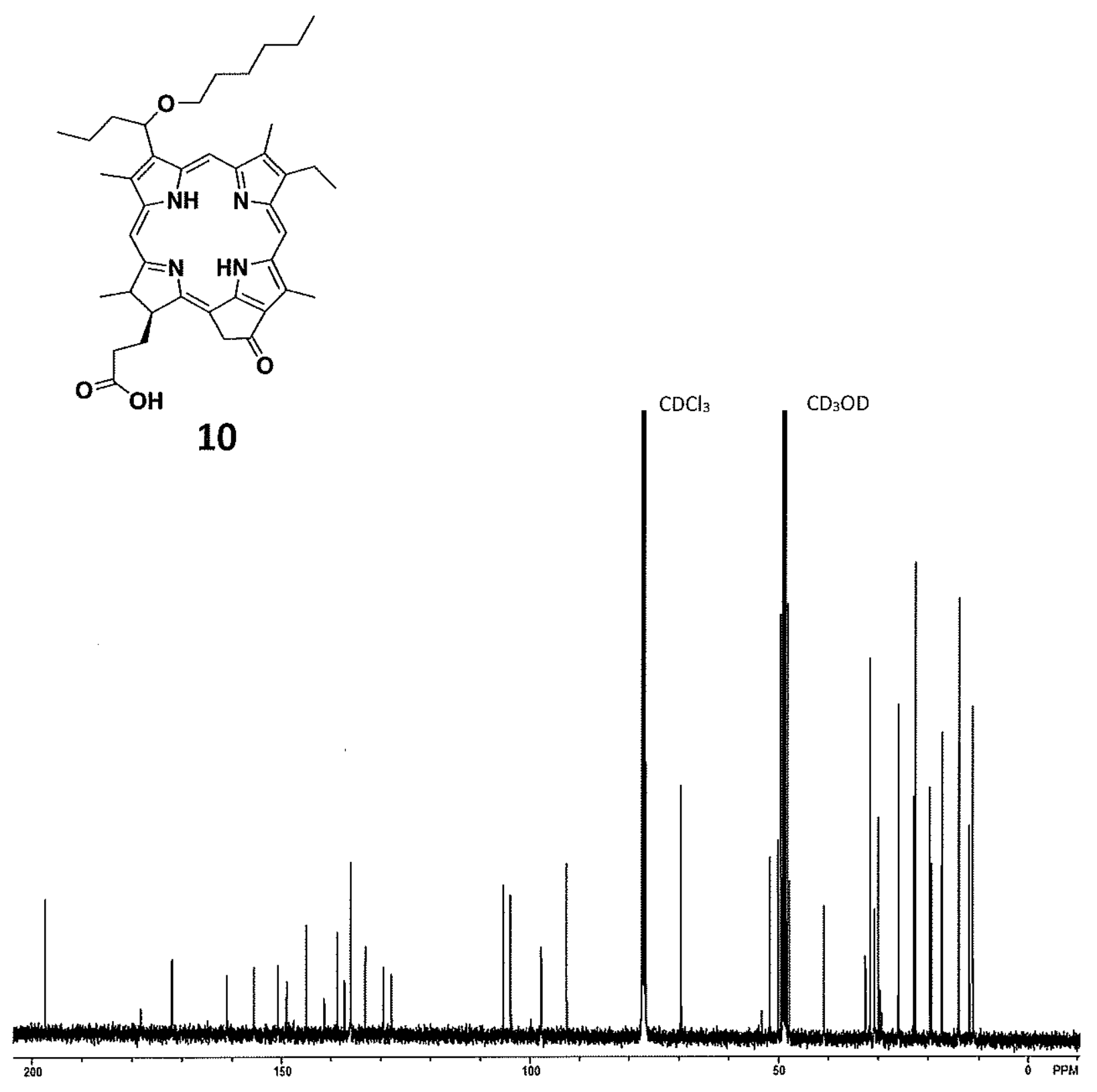


Figure S21: ${ }^{1} \mathrm{H} \mathrm{NMR}\left(\mathrm{CDCl}_{3}, 400 \mathrm{MHz}\right)$

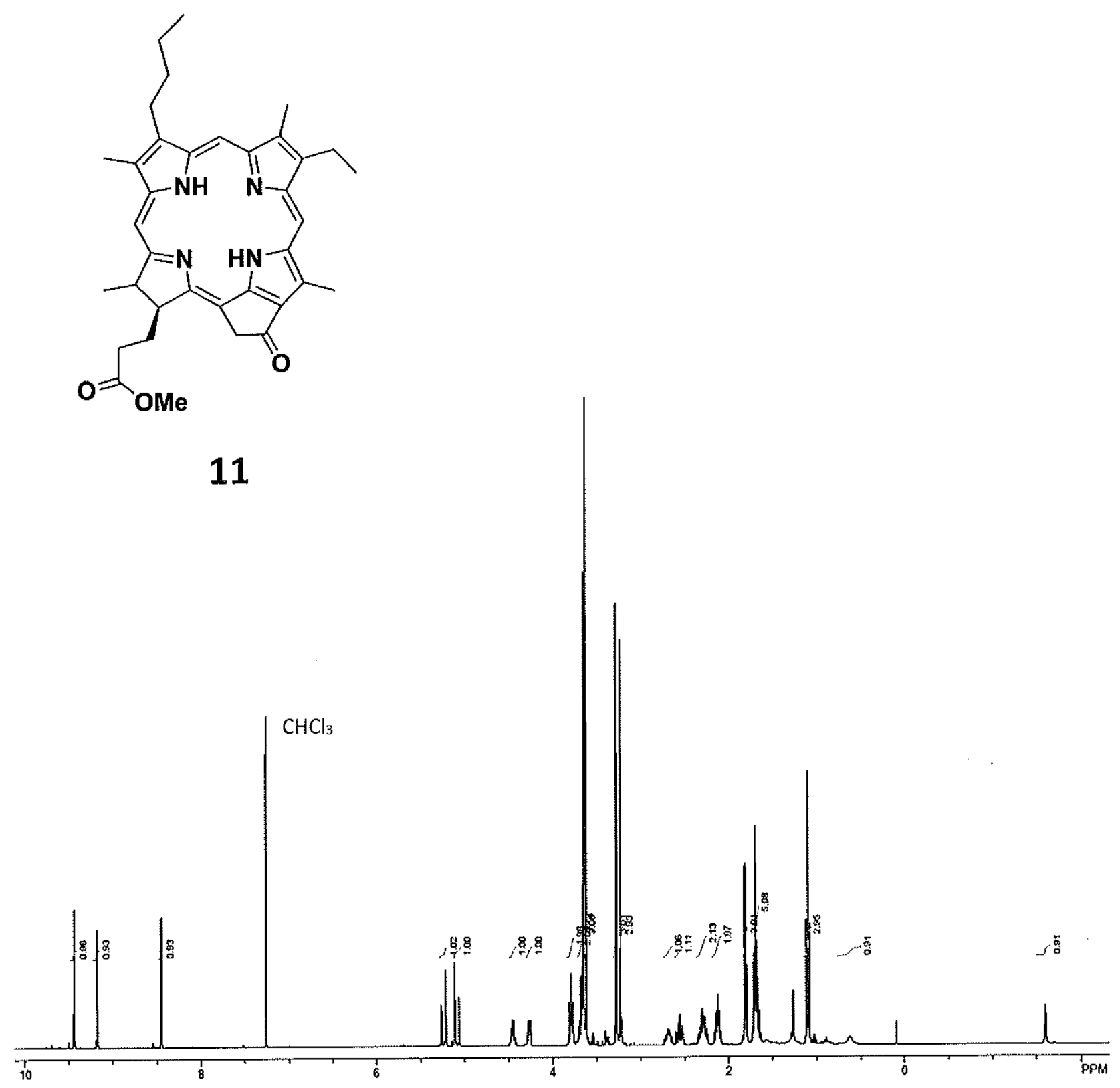


Figure $\mathrm{S} 22:{ }^{13} \mathrm{C} \mathrm{NMR}\left(\mathrm{CDCl}_{3}, 100 \mathrm{MHz}\right)$

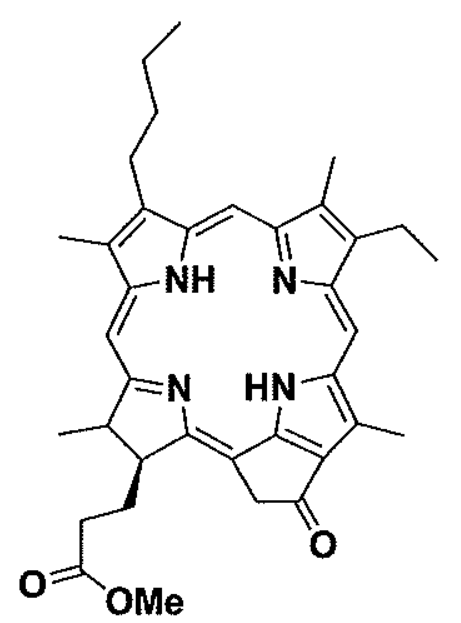

11

$\mathrm{CDCl}_{3}$

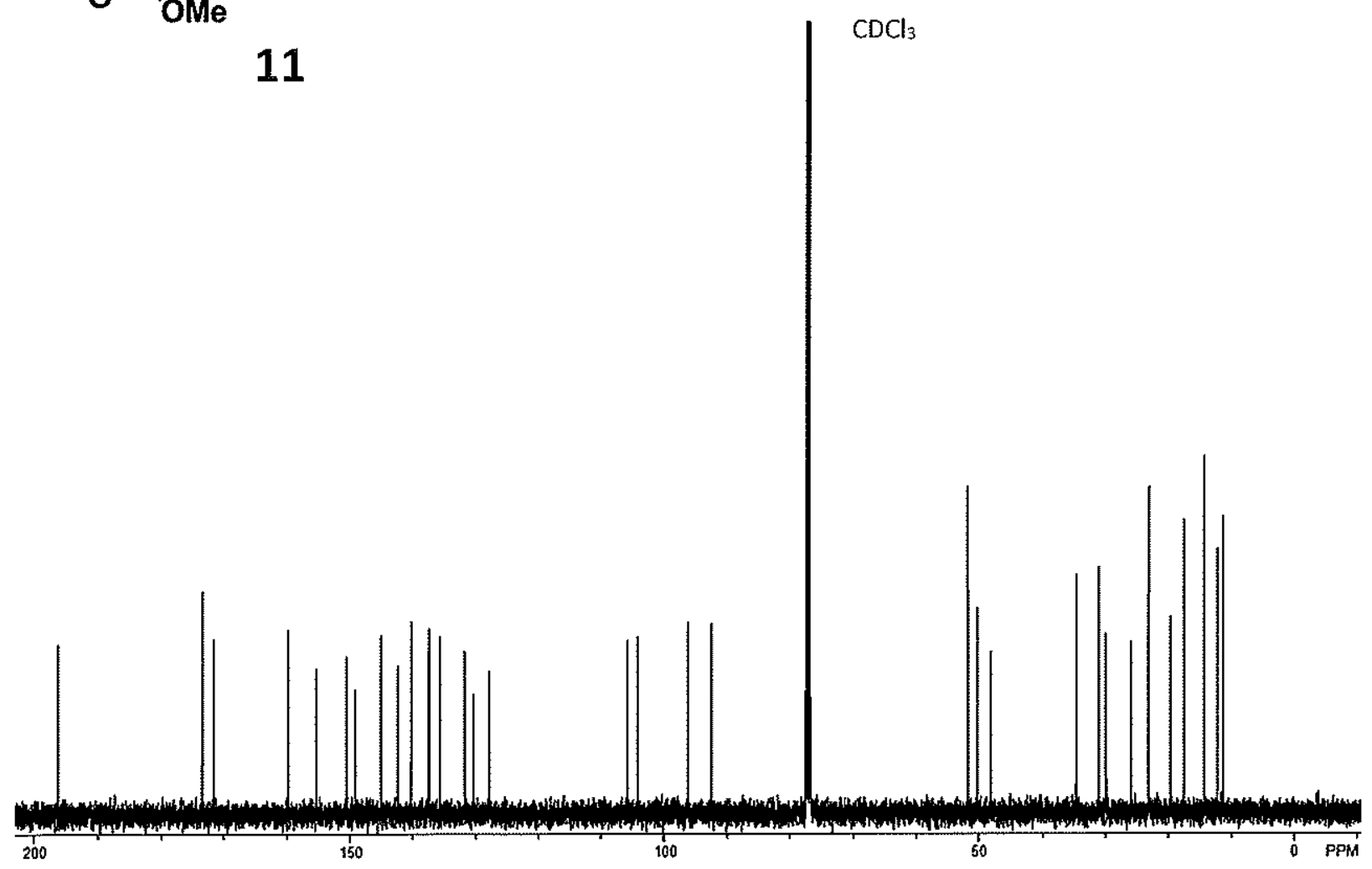


Figure S23: ${ }^{1} \mathrm{H} \mathrm{NMR}\left(\mathrm{CDCl}_{3}, 400 \mathrm{MHz}\right)$

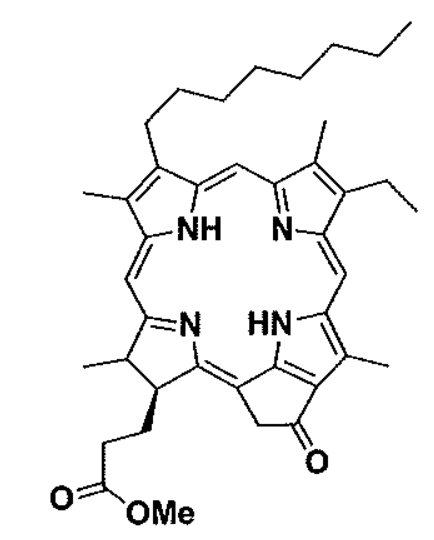

13

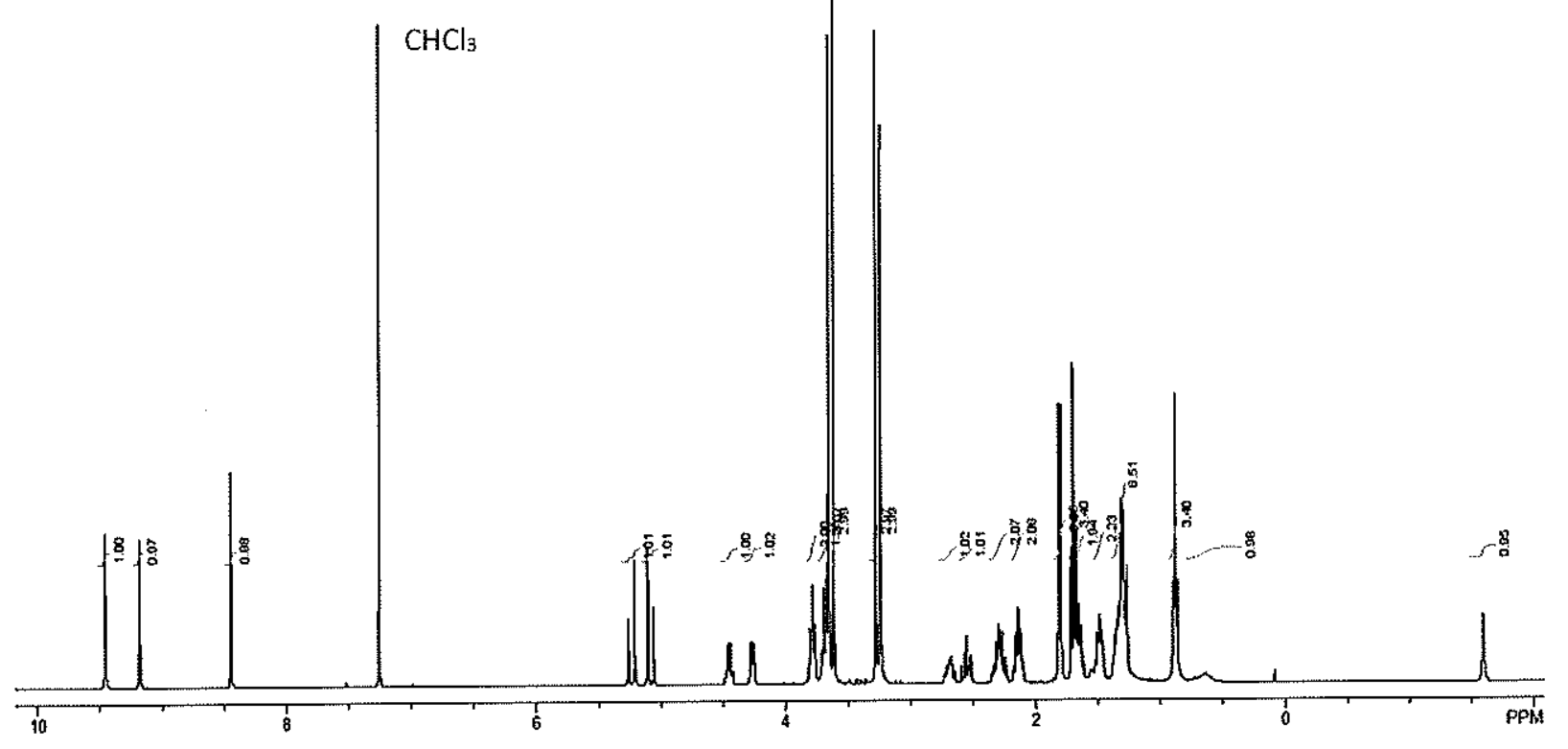


Figure S24: ${ }^{13} \mathrm{C} \mathrm{NMR}\left(\mathrm{CDCl}_{3}, 100 \mathrm{MHz}\right)$

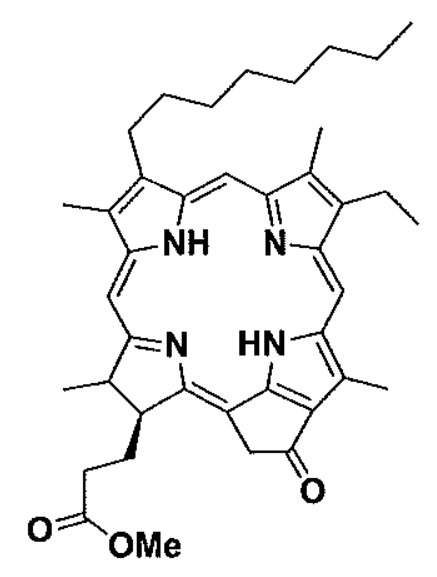

13

$\mathrm{CDCl}_{3}$

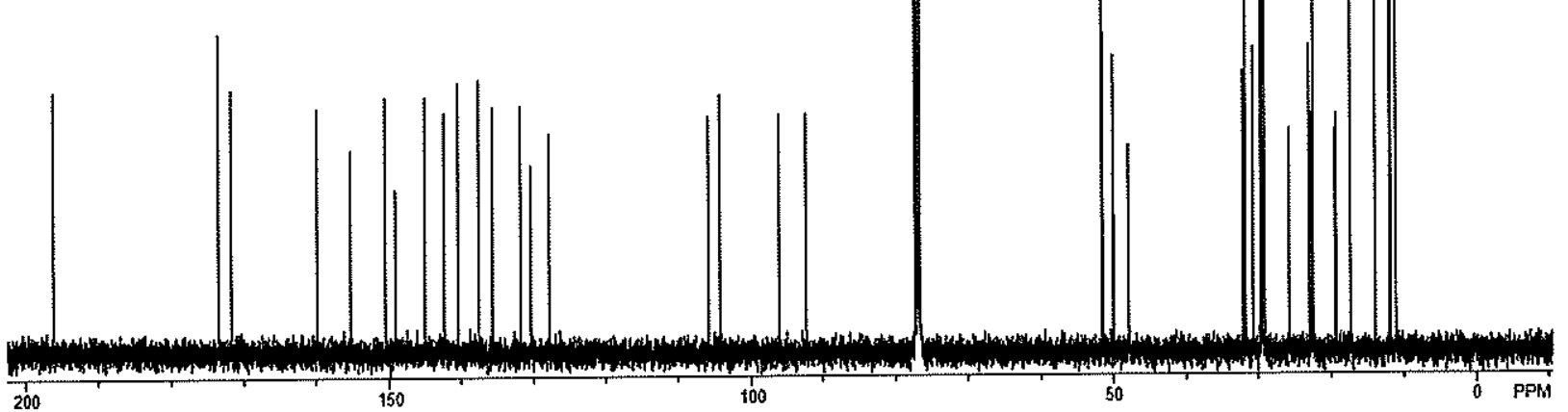


Figure S25: ${ }^{1} \mathrm{H} \mathrm{NMR}\left(\mathrm{CDCl}_{3}, 400 \mathrm{MHz}\right)$

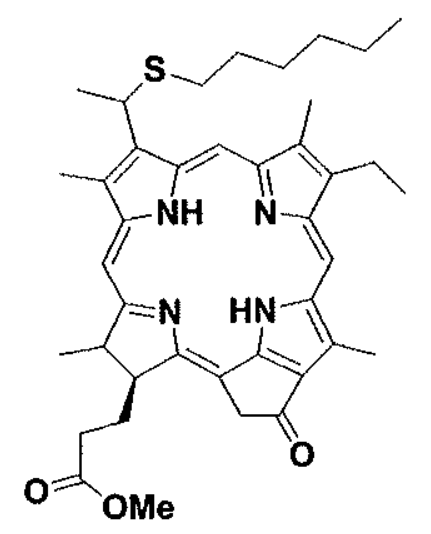

15

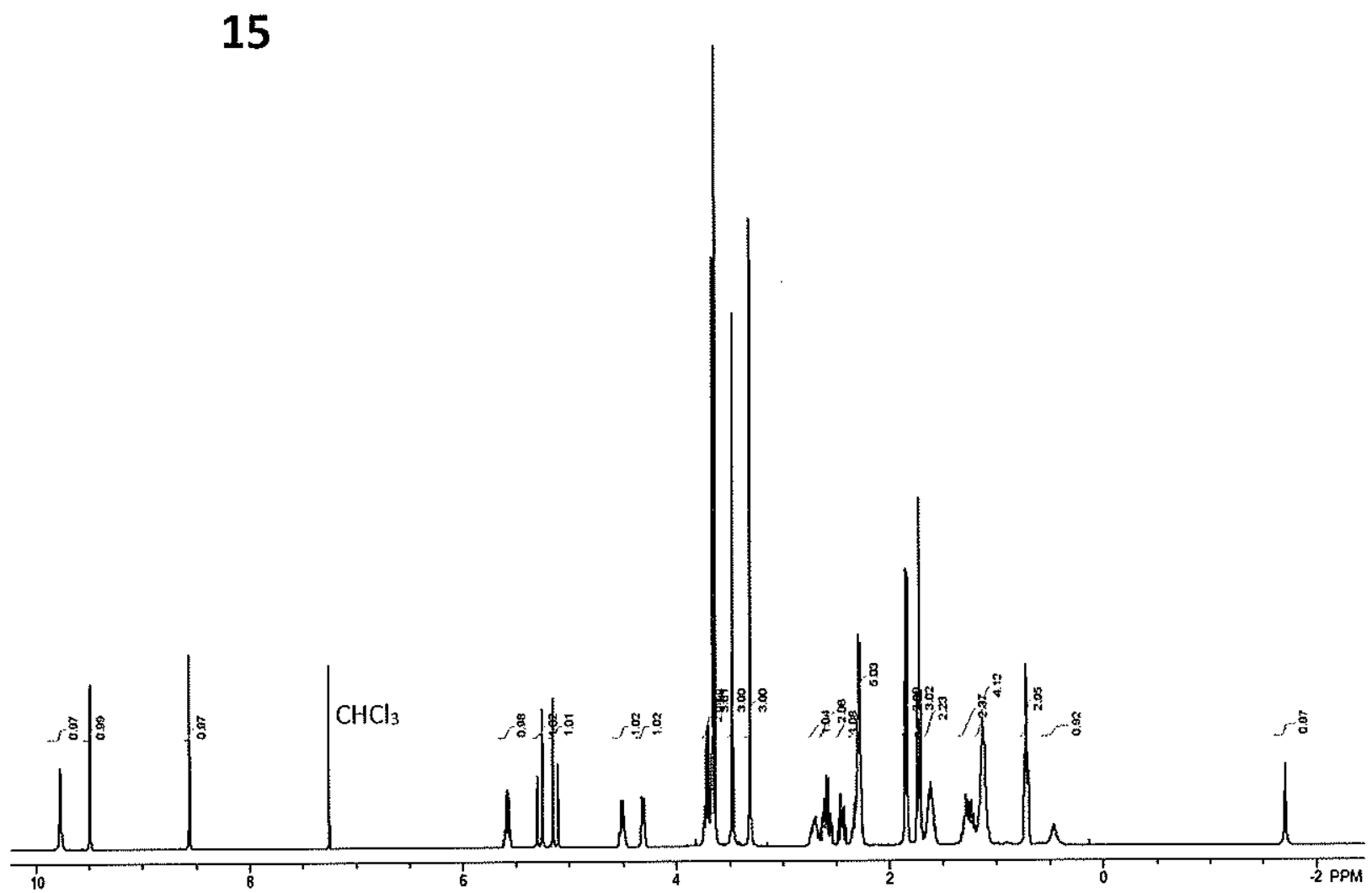


Figure S26: ${ }^{13} \mathrm{C} \mathrm{NMR}\left(\mathrm{CDCl}_{3}, 100 \mathrm{MHz}\right)$

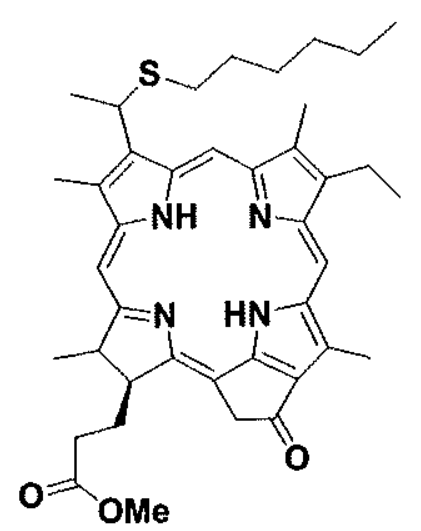

15

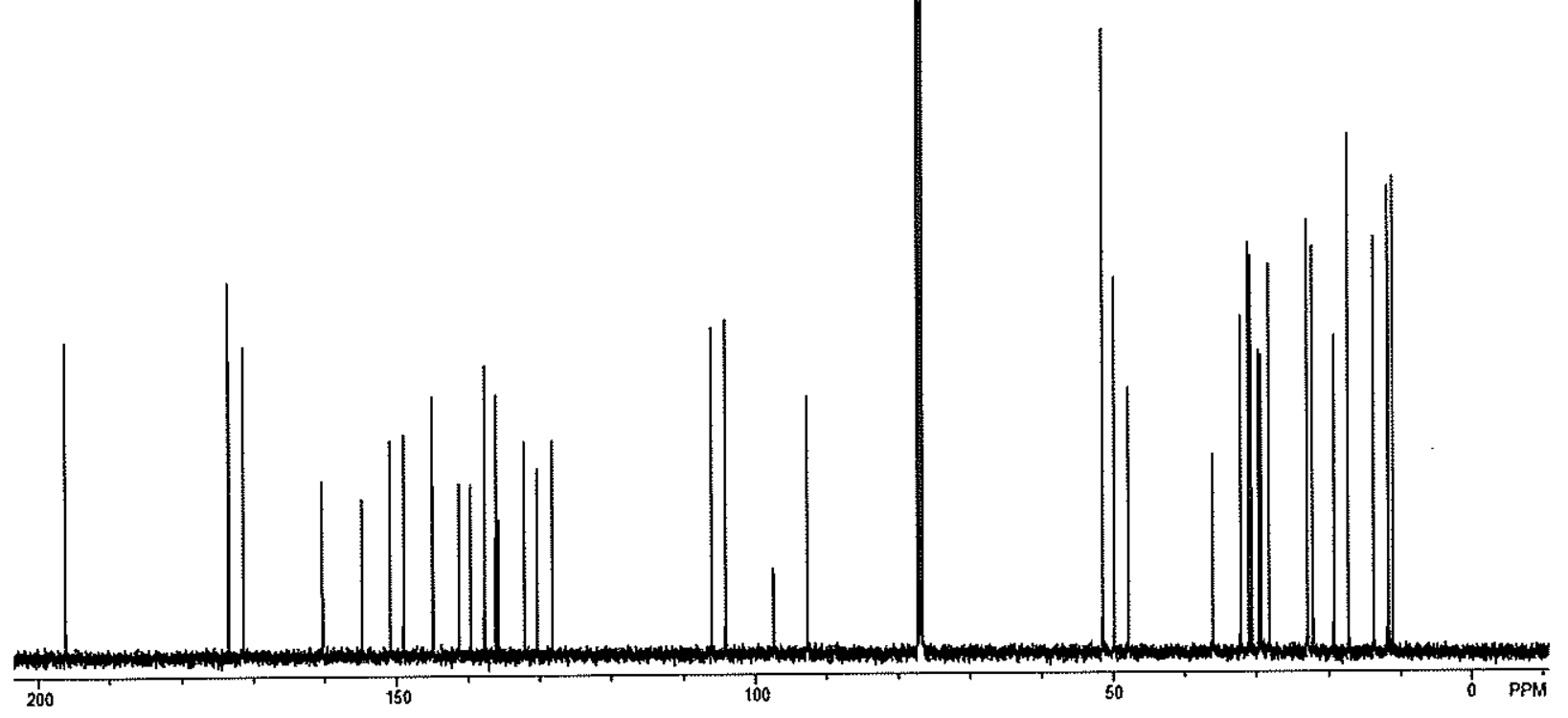


Figure S27: ${ }^{1} \mathrm{H}$ NMR (80:20 $\left.\mathrm{CDCl}_{3} / \mathrm{CD}_{3} \mathrm{OD}, 400 \mathrm{MHz}\right)$
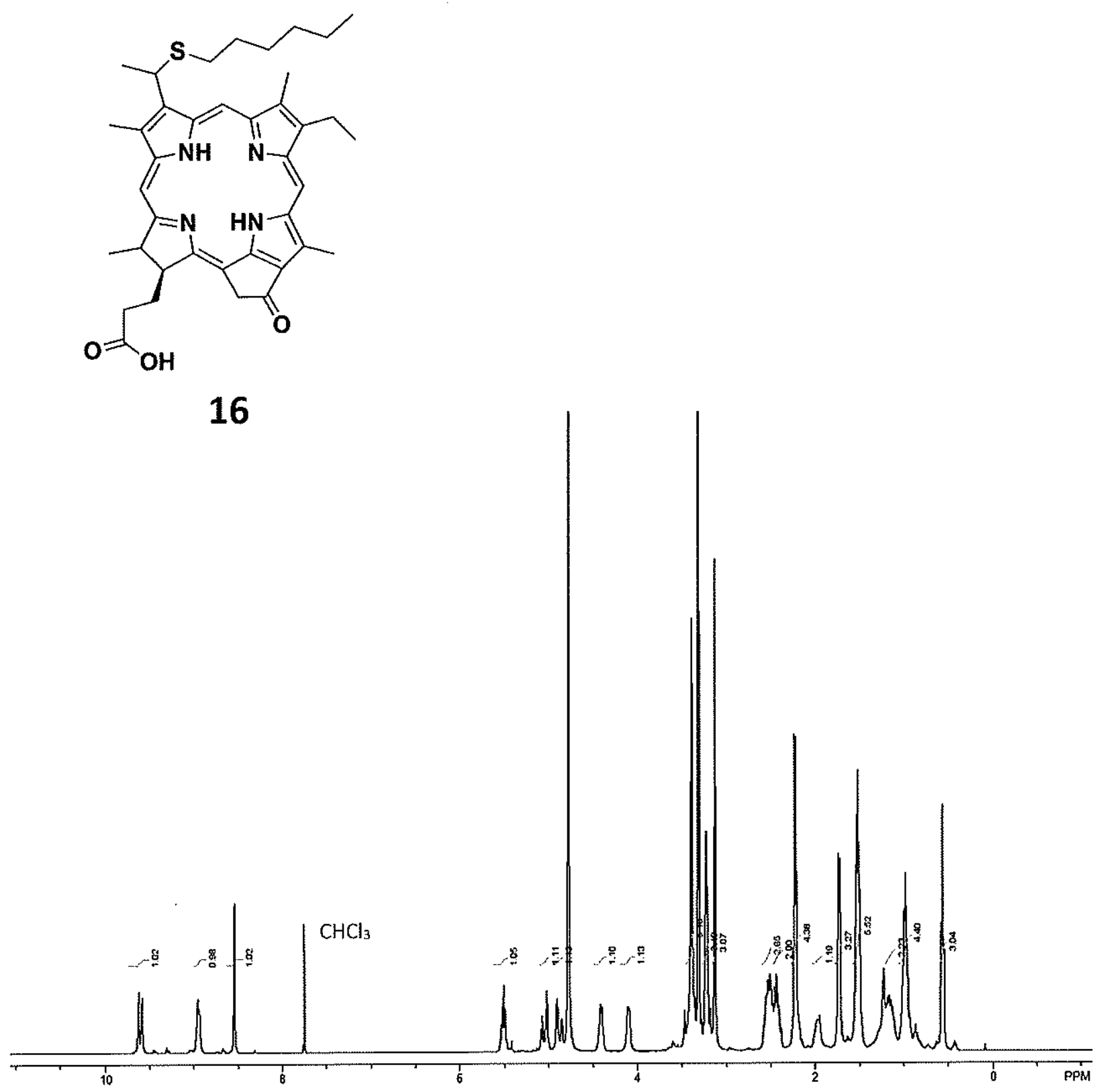
Figure S28: ${ }^{13} \mathrm{C}$ NMR (80:20 CDCl $\left./ \mathrm{CD}_{3} \mathrm{OD}, 100 \mathrm{MHz}\right)$

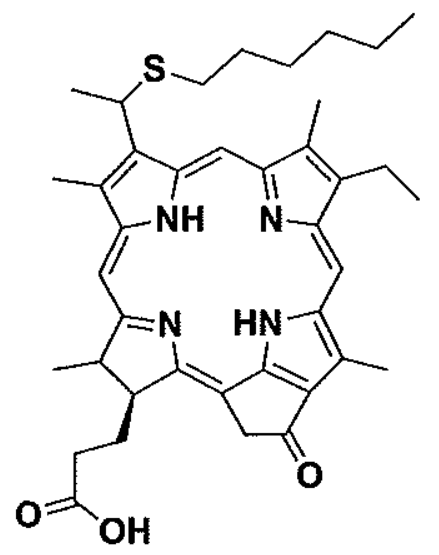

$\mathrm{CDCl}_{3} \quad \mathrm{CD}_{3} \mathrm{OD}$

16

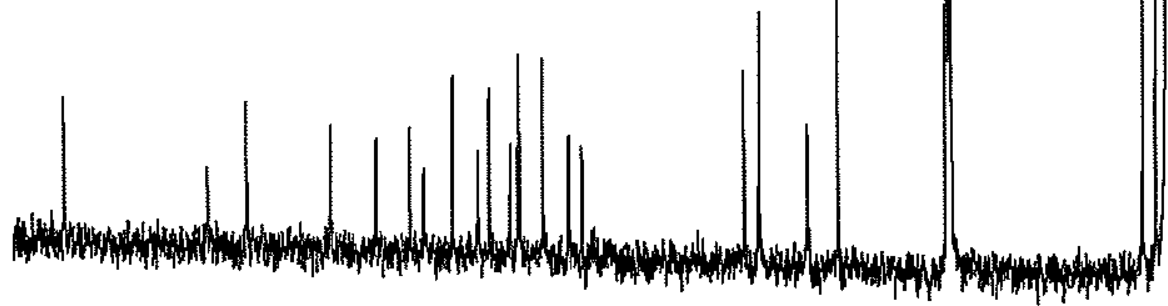

200

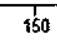

100

so

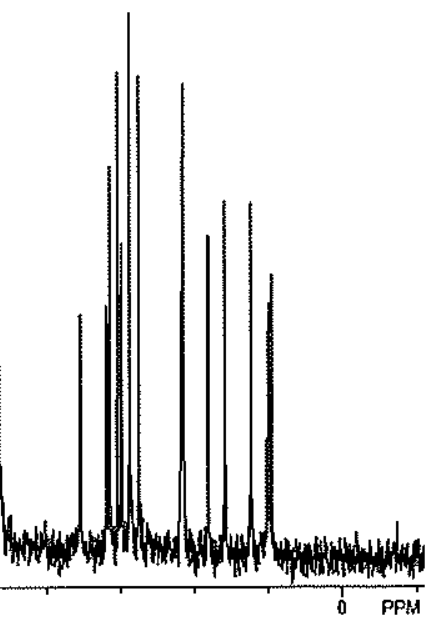


Figure S29: ${ }^{1} \mathrm{H} \mathrm{NMR}\left(\mathrm{CDCl}_{3}, 400 \mathrm{MHz}\right)$

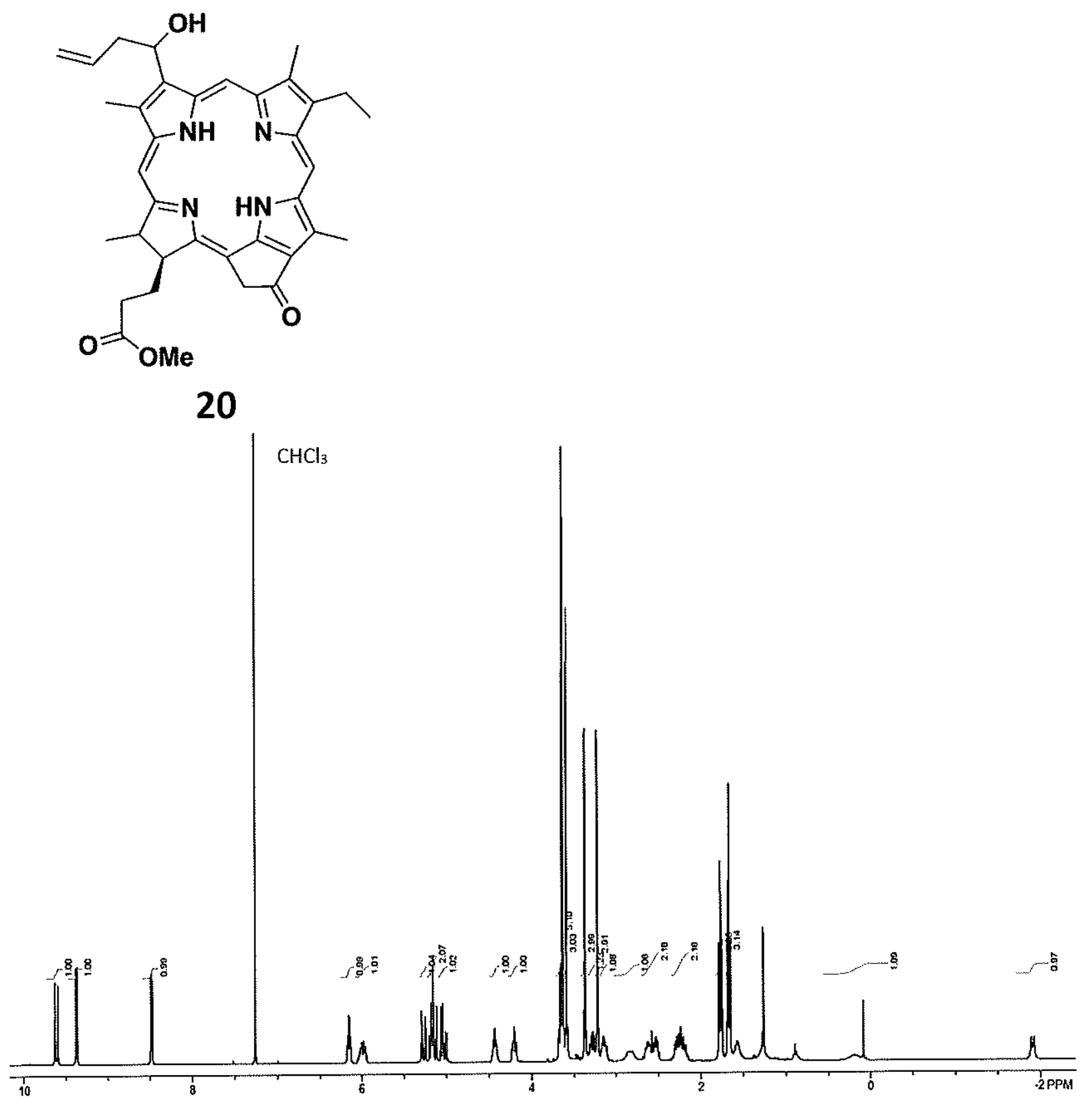


Figure S30: ${ }^{13} \mathrm{C} \mathrm{NMR}\left(\mathrm{CDCl}_{3}, 100 \mathrm{MHz}\right)$

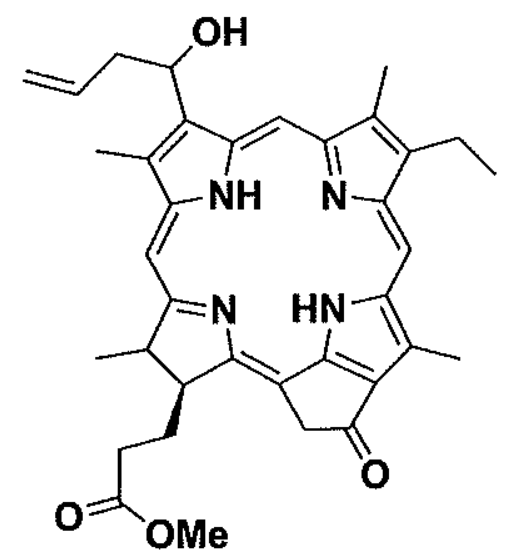

20

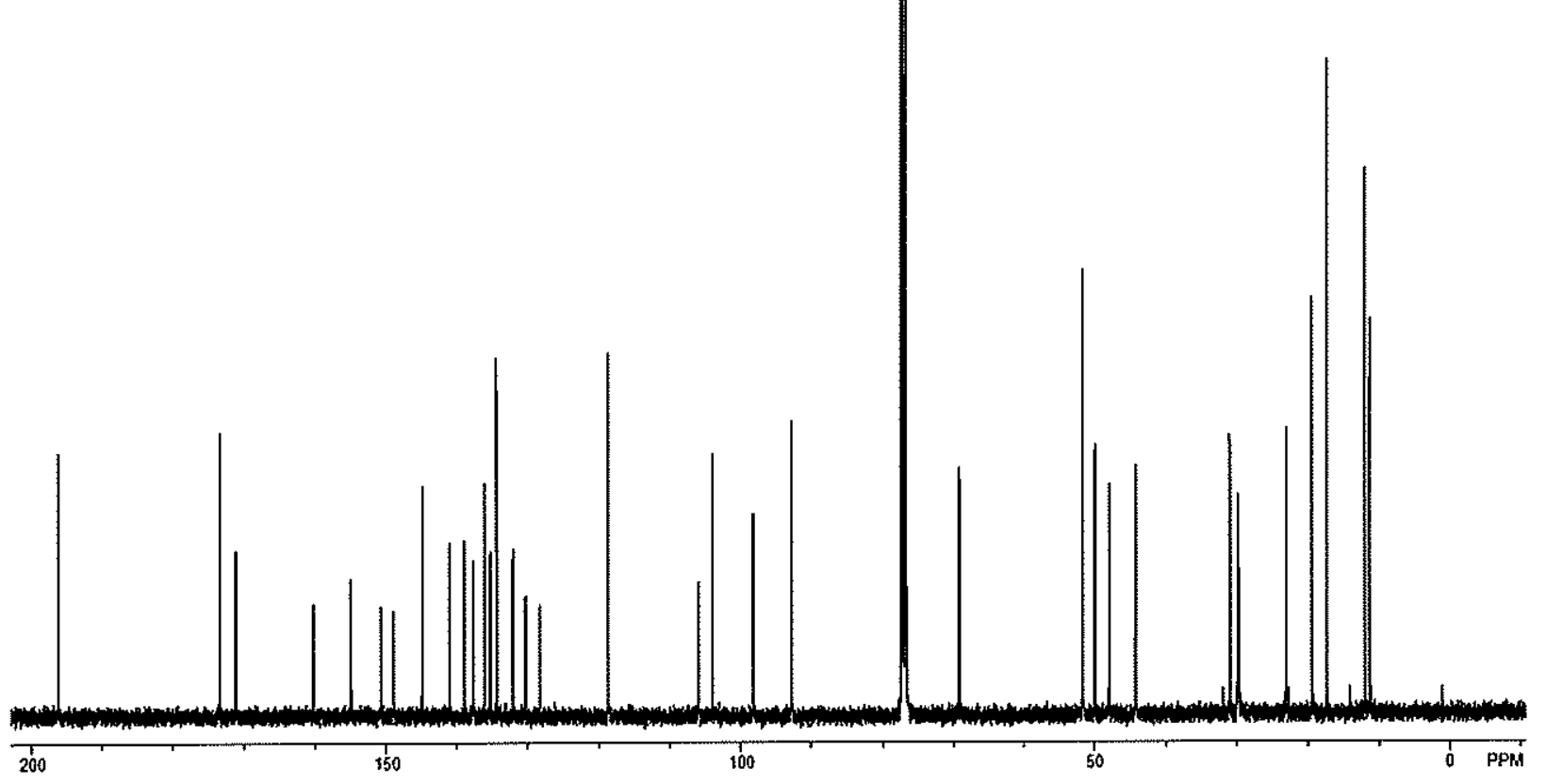


Figure S31: ${ }^{1} \mathrm{H} \mathrm{NMR}\left(\mathrm{CDCl}_{3}, 400 \mathrm{MHz}\right)$

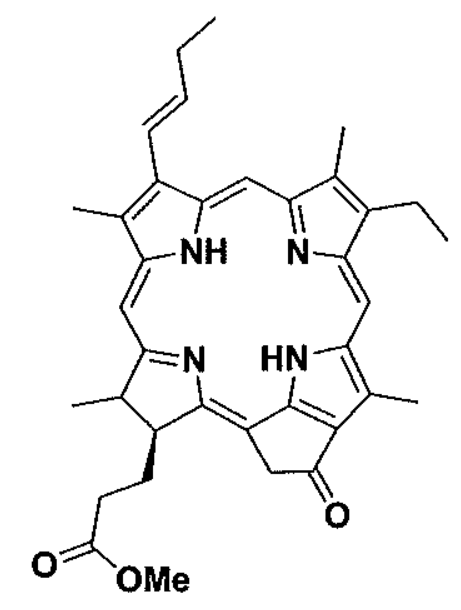


Figure S32: ${ }^{1} \mathrm{H} \mathrm{NMR}\left(\mathrm{CDCl}_{3}, 400 \mathrm{MHz}\right)$
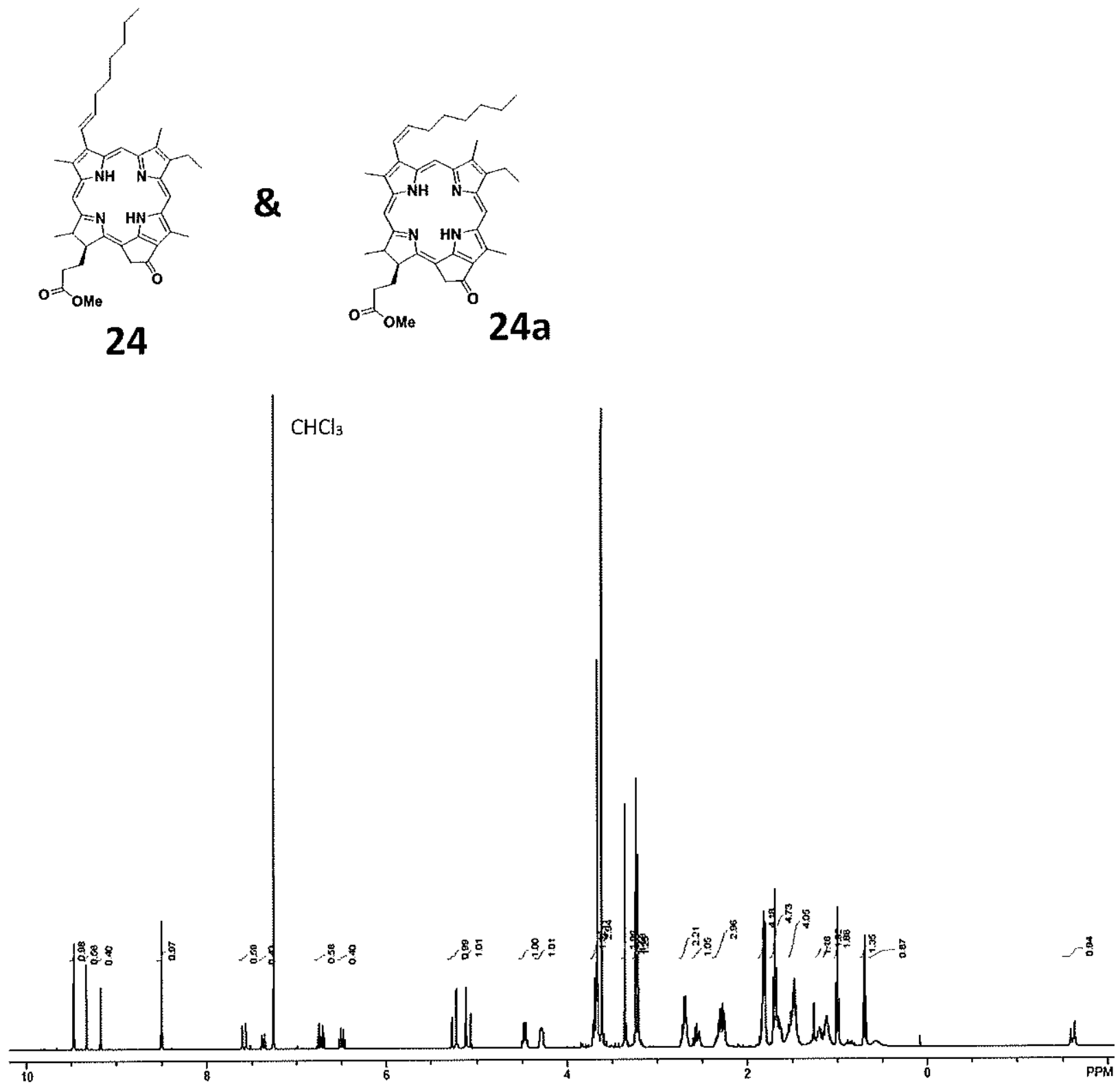
S36

Figure S33: ${ }^{13} \mathrm{C} \mathrm{NMR}\left(\mathrm{CDCl}_{3}, 100 \mathrm{MHz}\right)$
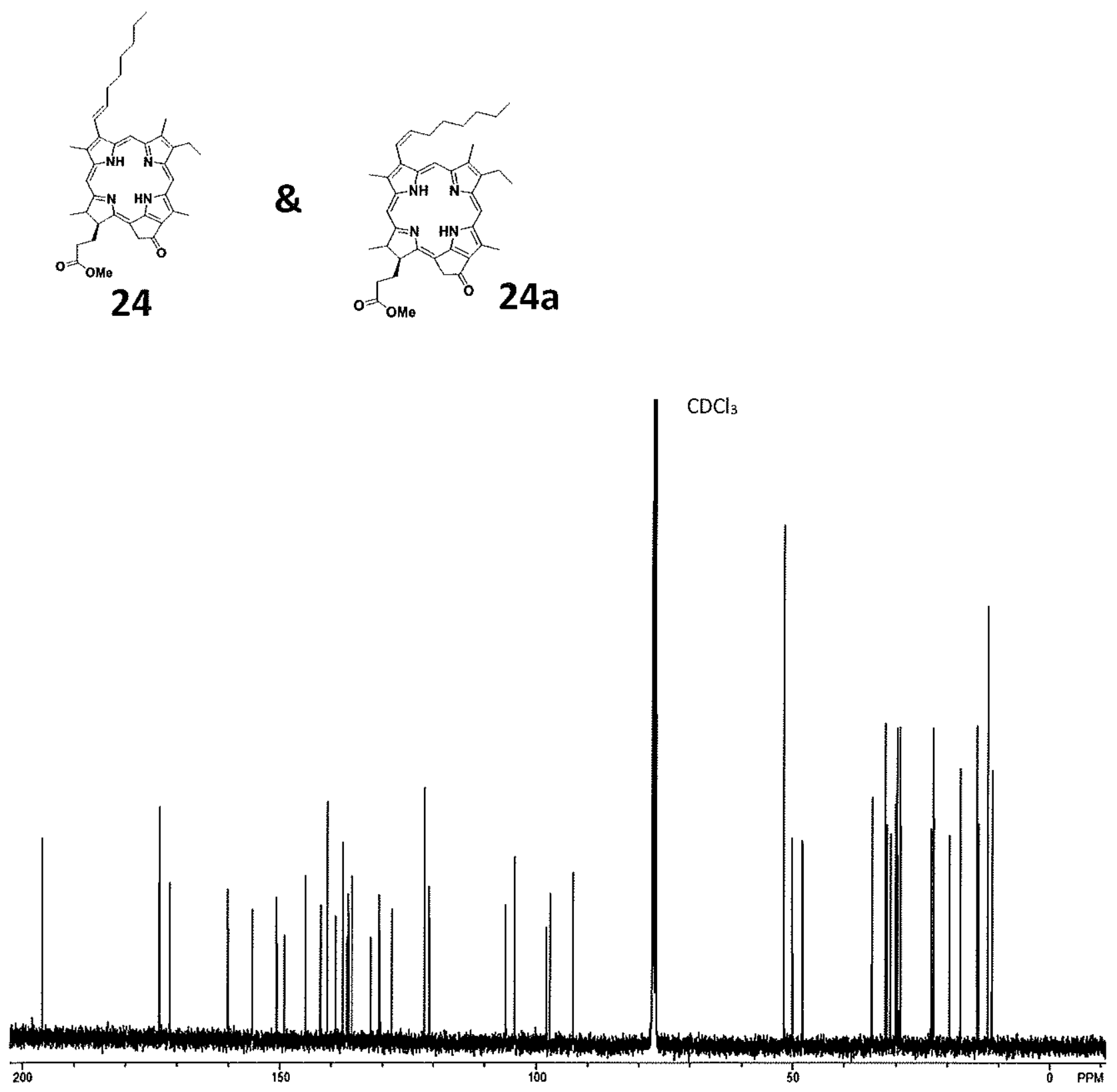


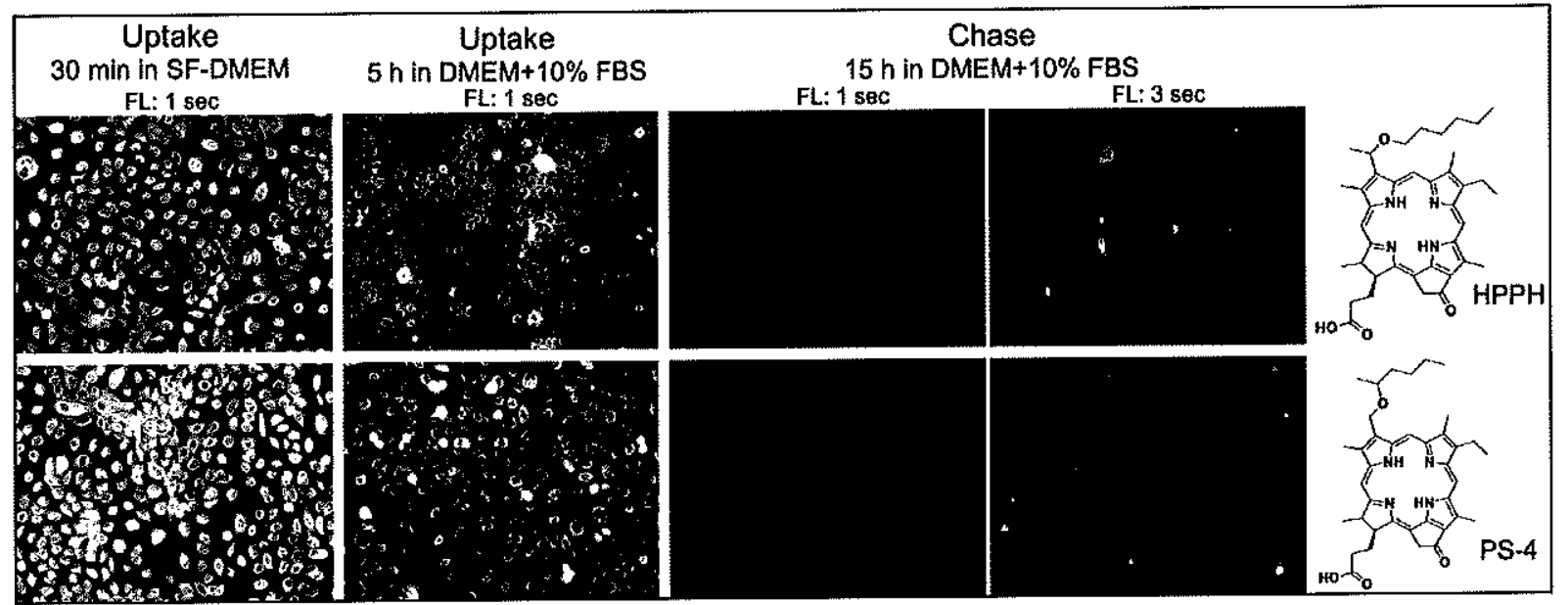

Figure \$34 Confluent monolayers of HNT1 cells (passage 116, low retaining activity for HPPH) were incubated either for $30 \mathrm{~min}$ at $37^{\circ} \mathrm{C}$ in serum-free DMEM containing $1.6 \mu \mathrm{M}$ of $\mathrm{HPPH}$ or PS-4 or $5 \mathrm{~h}$ at $37^{\circ} \mathrm{C}$ in DMEM containing $10 \% \mathrm{FBS}$ and $1.6 \mu \mathrm{M}$ of the same PSs. After imaging the cultures for the cellular level of PSs at $100 \mathrm{X}$ magnification, the cells were continued incubated for $15 \mathrm{~h}$ in DMEM containing 10\% FBS (Chase) to determine PS retention based on detection of the PS's fluorescence. 


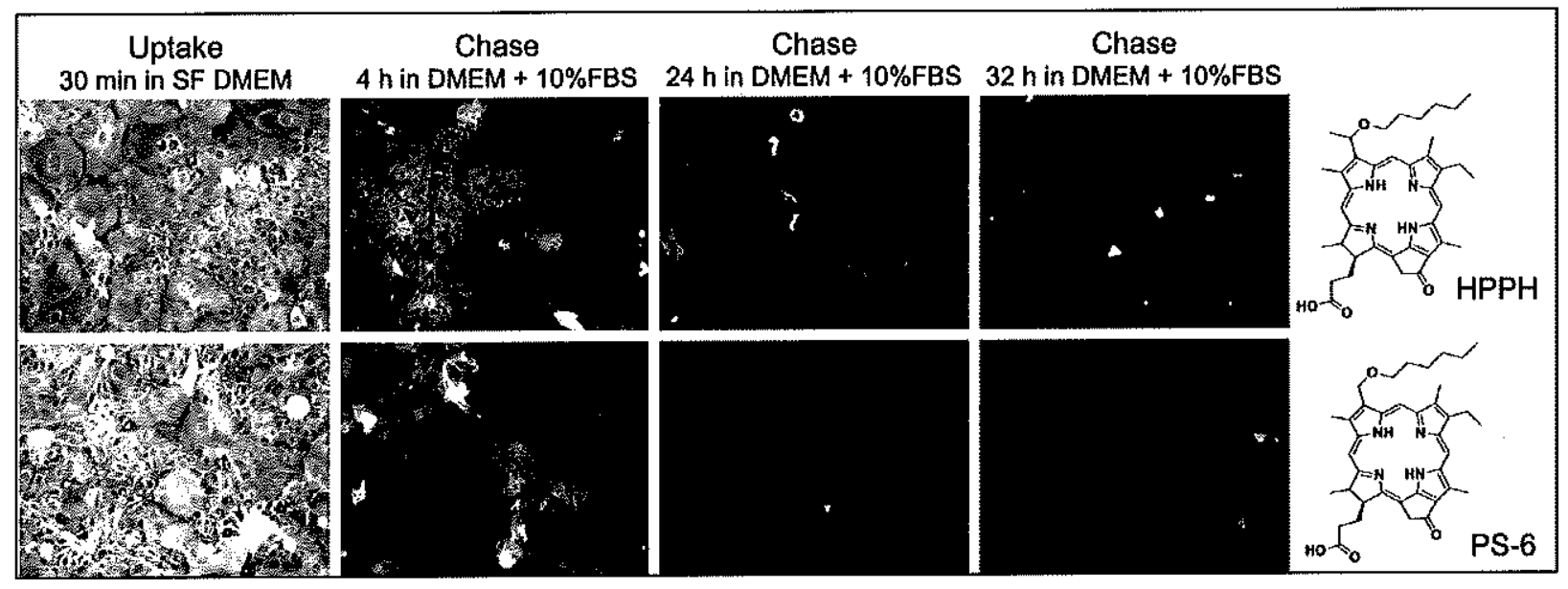

Figure S35 Comparison of HPPH with PS-6 to determine the effect of the chiral methyl group at position 3(1'). Confluent monolayers of HNT1 cells (passage 28 , high retaining activity for HPPH) treated with $1.6 \mu \mathrm{M}$ of the indicated PSs and cellular level of PSs imaged by fluorescent microscopy at $100 \mathrm{X}$ magnification using $1 \mathrm{sec}$ camera exposure for each culture and timepoint. 


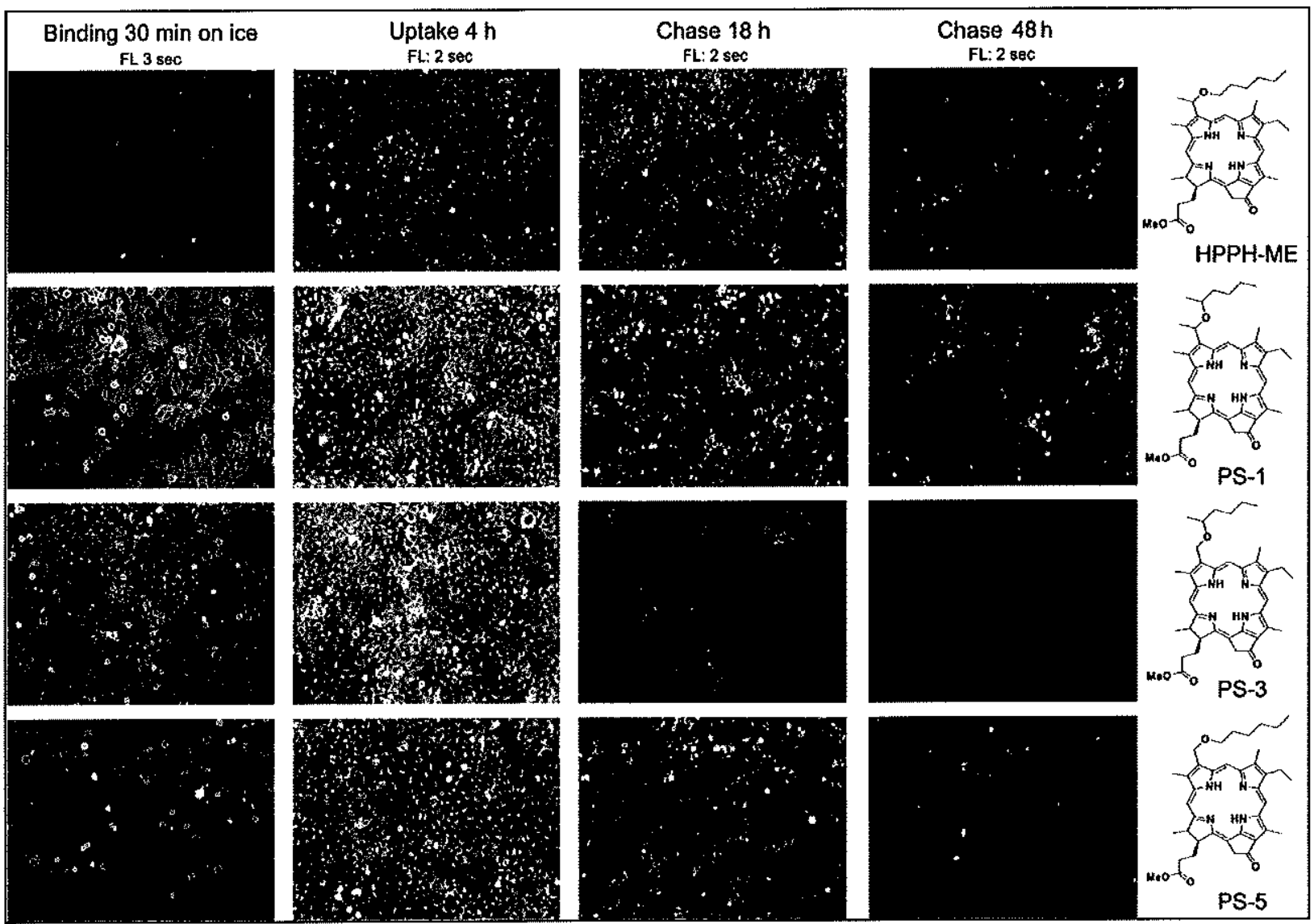

Figure S36. Testing the effect of chiral centers on the activity of methyl ester derivatives. Confluent monolayers of TEC-1-2 cells (passage 74) were treated for $30 \mathrm{~min}$ on ice with serumfree DMEM containing $1.6 \mu \mathrm{M}$ PSs or for $4 \mathrm{~h}$ at $37^{\circ} \mathrm{C}$ with DMEM containing $10 \%$ FBS and 1.6 $\mu \mathrm{M}$ PSs. Cellular retention of the PSs was imaged at $100 \mathrm{X}$ magnification followed by $18 \mathrm{~h}$ and $48 \mathrm{~h}$ chase periods. 


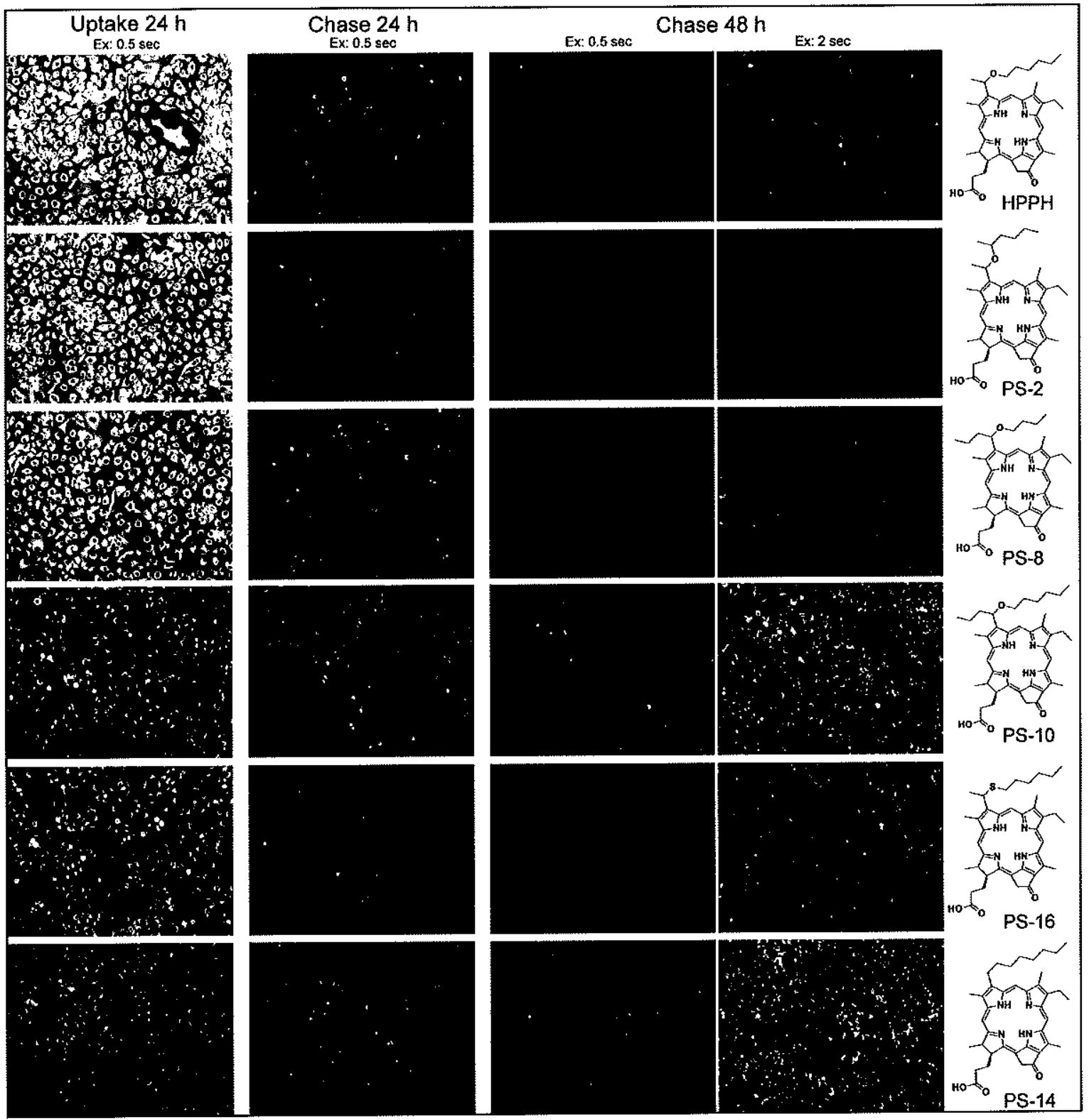

Figure \$37. Cellular retention of carboxylated PSs by tumor cells with low retention of HPPH. Confluent monolayers of HN-174 T-EC (passage 7) were incubated with RPMI containing $10 \%$ FBS and 1.6 $\mu \mathrm{M}$ PSs as indicated. Retention of the PSs were imaged after 24 and $48 \mathrm{~h}$ chase periods. 


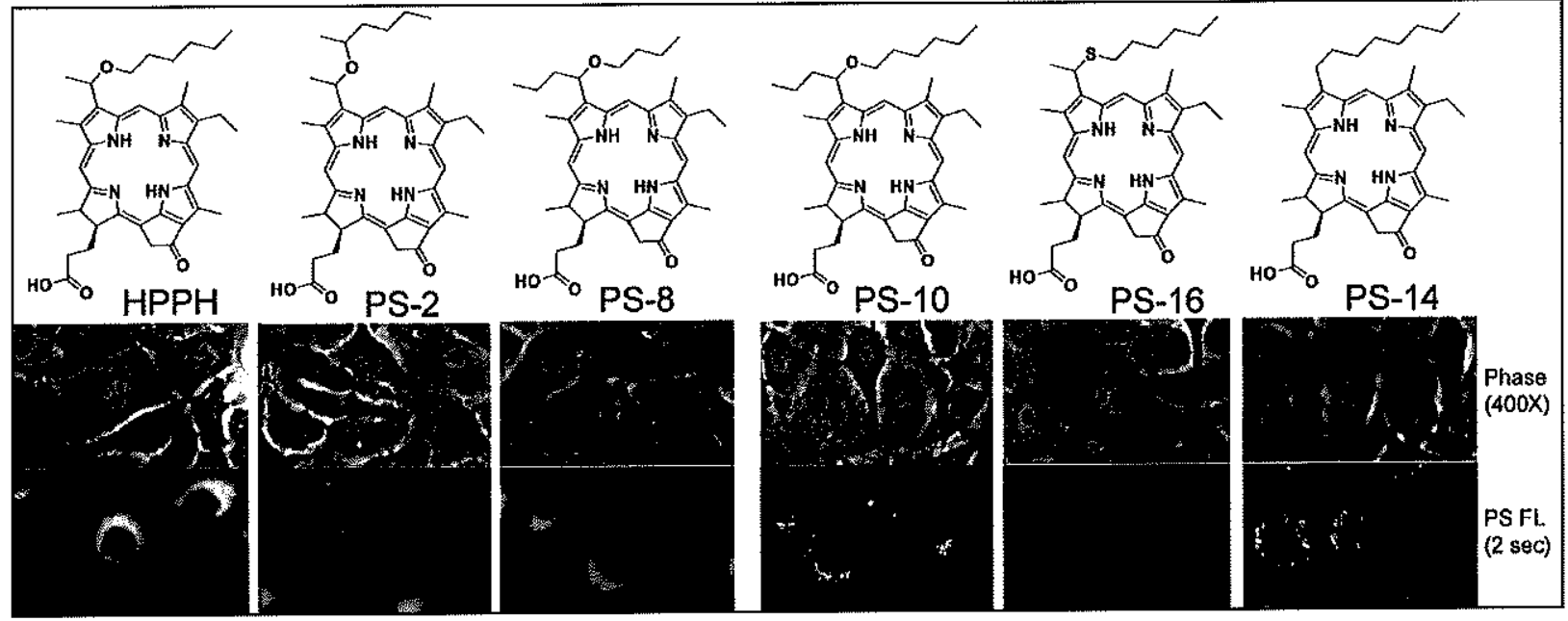

Figure S38. Subcellular location of the PSs after $24 \mathrm{~h}$ chase period. The cultures of HN-174 TEC (passage 7) used in Figure 37 after $24 \mathrm{~h}$ chase period were imaged by fluorescence microscopy at $400 \mathrm{X}$ magnification. 


\section{S42}

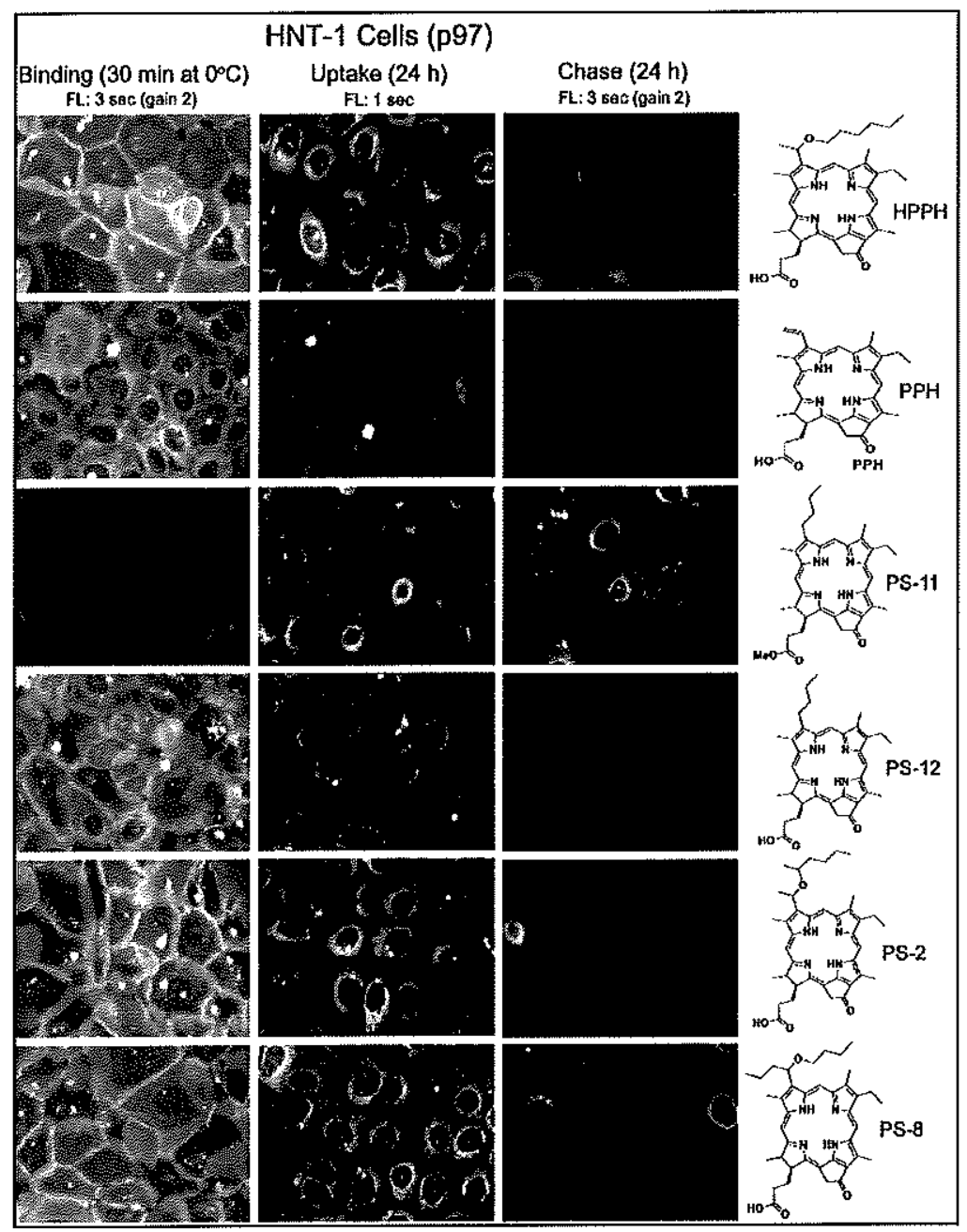

Figure S39: Effect of alkyl structures at position 3(1') on cell surface binding, uptake and retention. Confluent cultures of HNT1 cells (passage 97) were treated for $30 \mathrm{~min}$ on ice with serum-free DMEM containing $1.6 \mu \mathrm{M}$ PSs or for $24 \mathrm{~h}$ at $37^{\circ} \mathrm{C}$ with DMEM containing $10 \%$ FBS and $1.6 \mu \mathrm{M}$ PSs. Cellular levels of the PSs were imaged at $100 \mathrm{X}$ magnification. 
Table 1: Absorption (long wavelength), fluorescence, log $\mathrm{P}$ values and HPLC retention times of pyropheophorbide analogs

\begin{tabular}{|c|c|c|c|c|c|c|}
\hline \multirow{2}{*}{$\begin{array}{l}\text { Compound } \\
\text { Number }\end{array}$} & \multicolumn{2}{|c|}{$\begin{array}{l}\text { Uv/Vis, absorption (long wavelength) } \\
\text { intensity }\end{array}$} & \multicolumn{2}{|c|}{ Fluorescence, intensity } & \multirow{2}{*}{$\begin{array}{l}\text { Log } P \\
\text { (PALLAS } \\
\text { program) }\end{array}$} & \multirow{2}{*}{$\begin{array}{l}\text { HPLC }(\mathrm{RT} / \mathrm{min})^{*} \\
\text { (carboxylic acid } \\
\text { analogs only) } \\
{ }^{*} \text { (epimers) }\end{array}$} \\
\hline & $\begin{array}{l}\text { MeOH, absorption peak } \\
\text { extinction coefficient } \\
\text { value }\end{array}$ & $17 \%$ FBS/DPBS & $\mathrm{MeOH}$ & $\uparrow 7 \%$ FBS/DPBS & & \\
\hline 1 & $661,0,0.032(47,600)$ & $664.0,0.036$ & $664.0,428.19$ & $667.0,240.73$ & 6.67 & $x$ \\
\hline 2 & $661.0,0.042(45000$ & $665.0,0.043$ & $665.0,479.39$ & $668.0,187.6$ & 6.14 & $12.42,13.15$ \\
\hline 3 & $660.0,0.040(46,500)$ & $665.0,0.30$ & $665.0,476.35$ & $670.120,225.0$ & 6.30 & $x$ \\
\hline 4 & $659.0,0.03(47,400)$ & $664.0,0.41$ & $666.0,394.92$ & $670.0,219.19$ & 5.74 & 11.08 \\
\hline 5 & $660.0,0.035(46,400)$ & $665.0,0.50$ & $665.20,400.05$ & $671.0,215.00$ & 6.22 & $\mathrm{X}$ \\
\hline 6 & $661.0,0.038(46000)$ & $668.0,0.039$ & $665.00,402.00$ & $670.0,220.00$ & 5.58 & 12.35 \\
\hline 7 & $661.0,0.037(47,000)$ & $665.0,0.031$ & $664.0,464.7$ & $667.0,190.1$ & 6.62 & $x$ \\
\hline 8 & $660,0,0.038(46,500)$ & $665.0,0.035$ & $665.0,466.0$ & $668.10,210.00$ & 6.01 & 14.90 \\
\hline 9 & $660.0,0.037(47,000)$ & $665.0,0.031$ & $664.0,454.03$ & $667.0,163.55$ & 7.23 & $\mathrm{x}$ \\
\hline 10 & $661.0,0.039(45500)$ & $664.0,0.039$ & $664.0,455.83$ & $669.0,177.98$ & 6.56 & 23.76 \\
\hline 11 & $657.0,0.033(47,600)$ & $661.0,0.038$ & $661.0,430.4$ & $665.0,211.32$ & 6.04 & $x$ \\
\hline 12 & $656.0,0.035(46000)$ & $662.0,0.035$ & $664.0,428.00$ & $665.1,210.30$ & 5.45 & 13.22 \\
\hline 13 & $659.0,0.025(45,600)$ & $660.0,0.031$ & $660.0,369.16$ & $663.0,196.77$ & 7.25 & $\mathrm{X}$ \\
\hline 14 & $662.0,0.035(46000)$ & $663,0.042$ & $666.0,398.61$ & $665.0,263.21$ & 6.47 & 29.14 \\
\hline 15 & $663.0,0.042(45000)$ & $666.0,0.039$ & $669.0,374.95$ & $670.0,138.15$ & 6.83 & $\mathrm{x}$ \\
\hline 16 & $667.0,0.038(46000)$ & $669.0,0.038$ & $671.0,364.98$ & $672.0,177.92$ & 6.28 & $\begin{array}{l}\text { Not stable in } \\
\text { HPLC conditions }\end{array}$ \\
\hline & & & & & & \\
\hline
\end{tabular}

- Method(s) for HPLC analysis:

A . Instrument: Waters analytical system 600 connecter with 996 photodiode array detector and Delta 600 multi-solvent delivery unit

with millennium 3,05, 01 data-system.

B. HPLC parameter:

* Solvent flow rate: $1.0 \mathrm{~mL} / \mathrm{min}$

* Mobile Phase: Methanol (97\%), water (3\%) with $0.5 \%$ acetic acid.Data collected between $220 \mathrm{~nm}$ to $750 \mathrm{~nm}$, processed at wavelength I max: $409 \mathrm{~nm}$.

C. HPLC Column: Waters Symmetry, catalog WAT $045905(\mathrm{C} 18,4.6 \times 150 \mathrm{~nm}, 5 \mathrm{~m})$ 


\section{Table 2: Molecular Formula Strings/Biological Activity}

\begin{tabular}{|c|c|c|}
\hline Compounid NNo. & MOEFCULAR Dormula Strings & BIOLOGICAL Activity (Tumor Cefl specifidty/retention) \\
\hline & 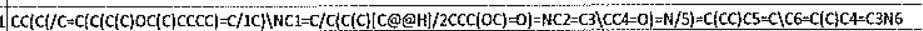 & HW- T1 cancercelts \\
\hline & 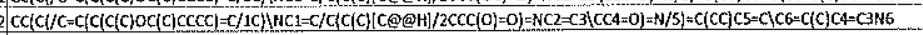 & $\mathrm{HN}-\mathrm{T} 1$ and $\mathrm{HN}-143$ cantel cells \\
\hline & 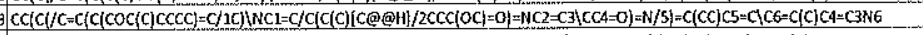 & HW-T1 cancer cells \\
\hline & 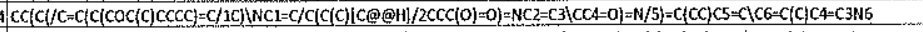 & Tunor-binding (in vivo\} TEC-21 lung cells: \\
\hline & 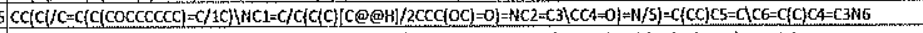 & MW-T1 tancer cells \\
\hline & 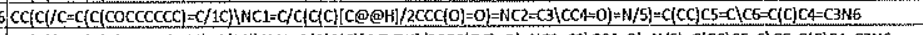 & $\mathrm{H} \cdot \mathrm{kT} 1$ ahd $\mathrm{HN}-143$ cancer cells \\
\hline & 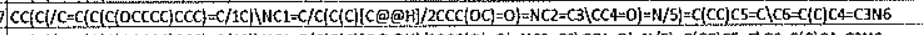 & HNI-T1 and HN-143 cancer cells \\
\hline & 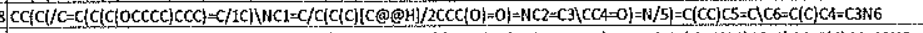 & Tumor-binding (in vivol TEC-21 lung cells \\
\hline & 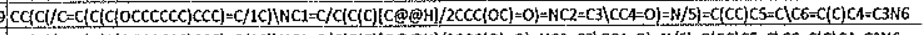 & HN-T1 and HN-143 cancer cells \\
\hline & 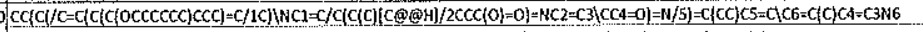 & HN-143 cancer cells \\
\hline & 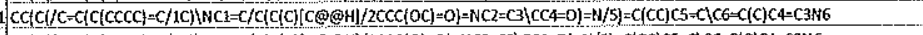 & \\
\hline & 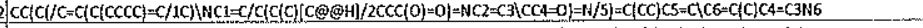 & \\
\hline & 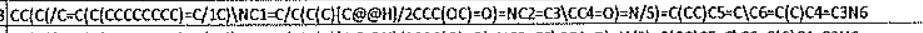 & \\
\hline & $4 \mid C C(C(/ C=C(C(C C C C C C C C)=C / 1 C) 1 N C 1=C / C(C(C), C @ @ H) / 2 C C C(O)=O)=N C 2=C 3) C C 4=0)=N / 5)=C(C C) C S=C(C 6=C(C) C 4-C 3 N 6$ & HN-T1 and HN143 cancer cells \\
\hline & 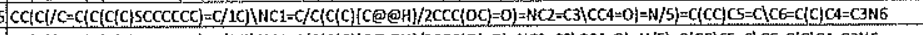 & HN-T1 and HN-143 cabcercells \\
\hline & 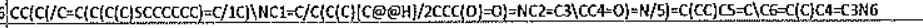 & HN- T1 and HN-143 cabcer cells \\
\hline HPPH & Known Compound & HN-T1 and HH-143 cancer cells Jumor bind!ng (in vivol TEC-21 lung cells \\
\hline
\end{tabular}


Page S45

HPLC Profiles of new compounds Investigated for Biological studies

Compound $2 \quad$ Page $\mathrm{S46}$

Compound $4 \quad$ Page $\$ 47$

Compound $6 \quad$ Page $\mathrm{S48}$

Compound $8 \quad$ Page $\$ 49$

Compound $10 \quad$ Page $\mathbf{S 5 0}$

Compound $12 \quad$ Page $\$ 51$

Compound $14 \quad$ Page S52

Compound $16 \quad$ Not stable 
Project Name HPPH

User Name System

Software Version 3.05.01
Report Method Name HPPHIrm 2

Current Date $\quad 12 / 11 / 20$

\section{Sample Information}

SampleName RKP-852-acid-081618

Column_info C18 symmetry $4.6 \times 150 \mathrm{~mm} 5 \mathrm{u}$

Injection Volume 20.00 ul

Mobile_phase $97 / 3: 0.5 \% \mathrm{AcOH}$ COH $\mathrm{H} / 0.5 \% \mathrm{AcOH}$
Date Acquired $\quad$ 8/16/18 11:33:31 An

Acq Method Set HPPH_

Processing Method 200_800procmeth

Date Processed 8/16/18 12:23:06 PM

Flow rate $1 \mathrm{ml} / \mathrm{min}$

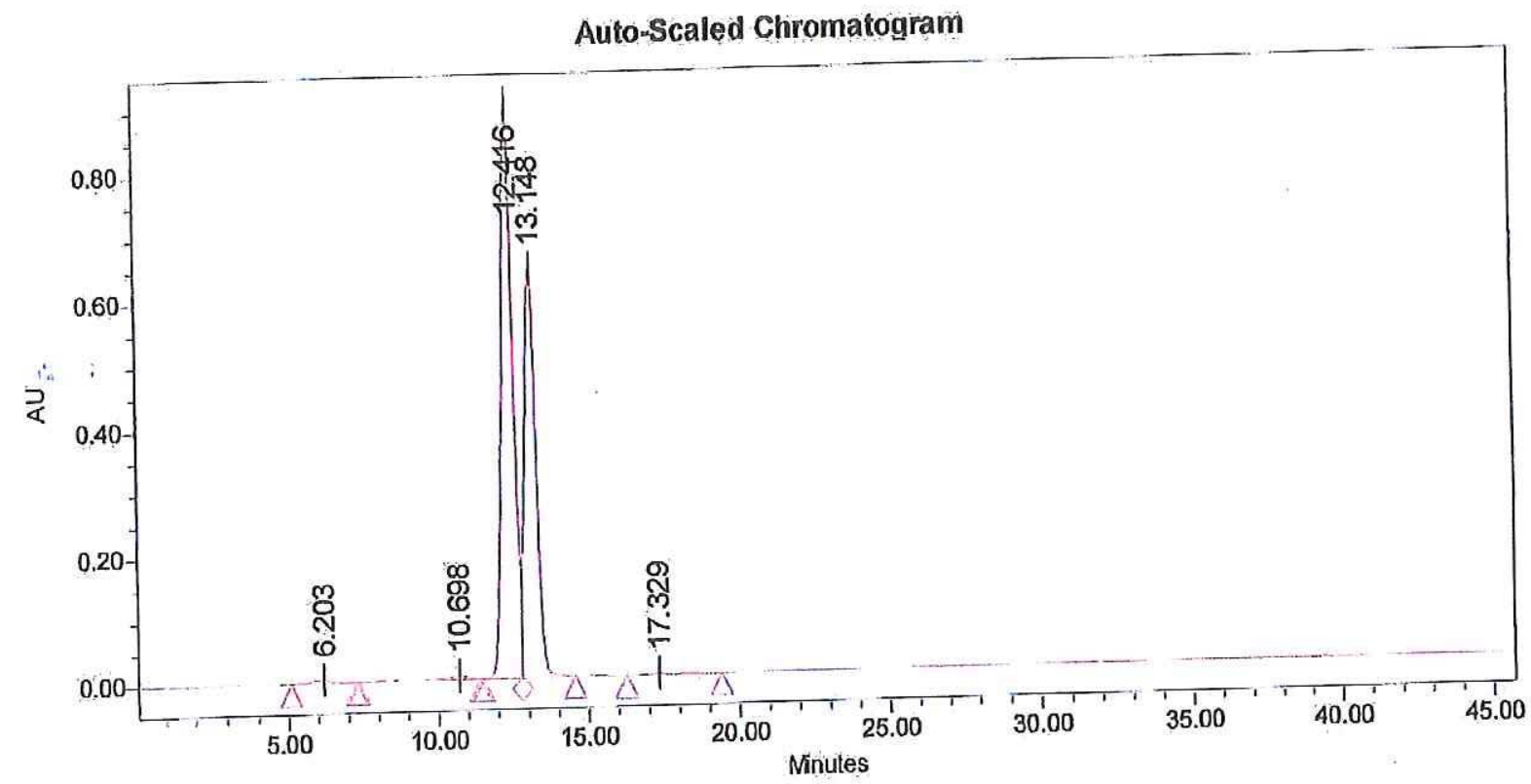

Peak Results

\begin{tabular}{|r|r|r|r|r|r|}
\hline 52 & Name & RT & \multicolumn{1}{c|}{ Area } & Height & \% Area \\
\hline 1 & & 6.203 & 275548 & 6580 & 0.65 \\
\hline 2 & & 10.698 & 395690 & 5792 & 0.94 \\
\hline 3 & & 12.416 & 24025536 & 903703 & 56.97 \\
\hline 4 & & 13.148 & 17318184 & 644235 & 41.06 \\
\hline 5 & & 17.329 & 157761 & 2632 & 0.37 \\
\hline
\end{tabular}

PDA Result Table

\begin{tabular}{|c|c|c|c|c|c|c|c|}
\hline & Name & RT & $\begin{array}{l}\text { Purity1 } \\
\text { Angle }\end{array}$ & $\begin{array}{c}\text { Purity1 } \\
\text { Threshold }\end{array}$ & $\begin{array}{c}\text { Match1 } \\
\text { Spect. Name }\end{array}$ & $\begin{array}{l}\text { Match1 } \\
\text { Angle }\end{array}$ & $\begin{array}{l}\text { Match1 } \\
\text { Threshold }\end{array}$ \\
\hline & & 6.203 & 6.457 & 1.210 & & & \\
\hline
\end{tabular}


Project Name HPPH

User Name System

Report Method Name HPPHm_2

Software Version 3.05.01

Current Date

$12 / 11 / 20$

\section{Sample Information}

SampleName RR-3-CH2-O-2-Hex-Acid-081518

Column_info C18 symmetry $4.6 \times 150 \mathrm{~mm} 5 \mathrm{u}$

Injection Volume $\quad 20.00 \mathrm{ul}$

Mobile_phase 97/3: 0.5\% AcOHMeOH/0.5\% AcO:

Flow_rate $1 \mathrm{ml} / \mathrm{min}$
Date Acquired $\quad$ 8/15/18 1:38:03 PM

Acq Methad Set HPPH

Processing Method 200_800procmeth

Date Processed $\quad 8 / 15 / 182227: 55$ PM

Channel Name $408 \mathrm{~nm}$

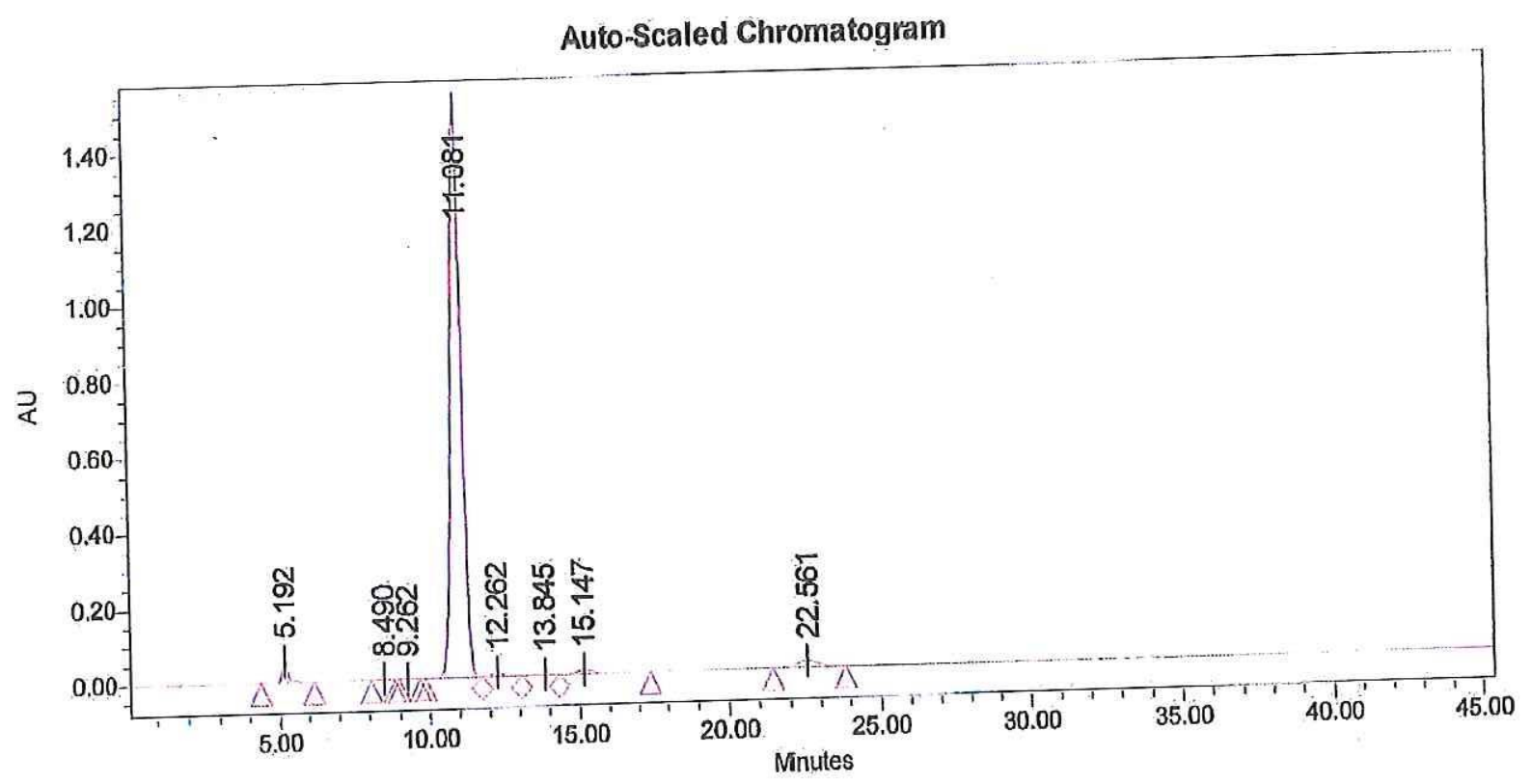

Peak Results

\begin{tabular}{|r|r|r|r|r|r|}
\hline Sq & Name & RT & \multicolumn{1}{|c|}{ Area } & Helght & $\%$ Area \\
\hline 1 & & 5.192 & 802604 & 58200 & 1.94 \\
\hline 2 & & 8.490 & 57801 & 3184 & 0.14 \\
\hline 3 & & 9.262 & 19635 & 921 & 0.05 \\
\hline 4 & & 11.081 & 38494080 & 1502821 & 93.19 \\
\hline 5 & & 12.262 & 416347 & 11424 & 1.01 \\
\hline 6 & & 13.845 & 187216 & 3546 & 0.45 \\
\hline 7 & & 15.147 & 423834 & 11530 & 1.03 \\
\hline 8 & & 22.561 & 907190 & 18367 & 2.20 \\
\hline
\end{tabular}


Project Name HPPH

User Name System

Report Method Name HPPHIm_2

Software Version 3.05 .01

Current Date

$12 / 11 / 20$

\section{Sample Information}

SampleName RR-3-CH2-O-Hex-Acid-081518

Column info C18 symmetry $4,6 \times 150 \mathrm{~mm} 5 \mathrm{u}$

Injection Volume $\quad 20.00 \mathrm{ul}$

Mobile phase $97 / 3: 0.5 \%$ AcOHMeOH/0.5\% AcO

Flow_rate $1 \mathrm{ml} / \mathrm{min}$
Date Acquired $\quad$ 8/15/18 11:53:12 AM

Acq Method Set HPPH

Processing Method 200_800procmeth

Date Processed $\quad 8 / 15 / 18$ 12:47:43 PM

Channel Name $408 \mathrm{~nm}$

Auto-Scaled Chromatogram

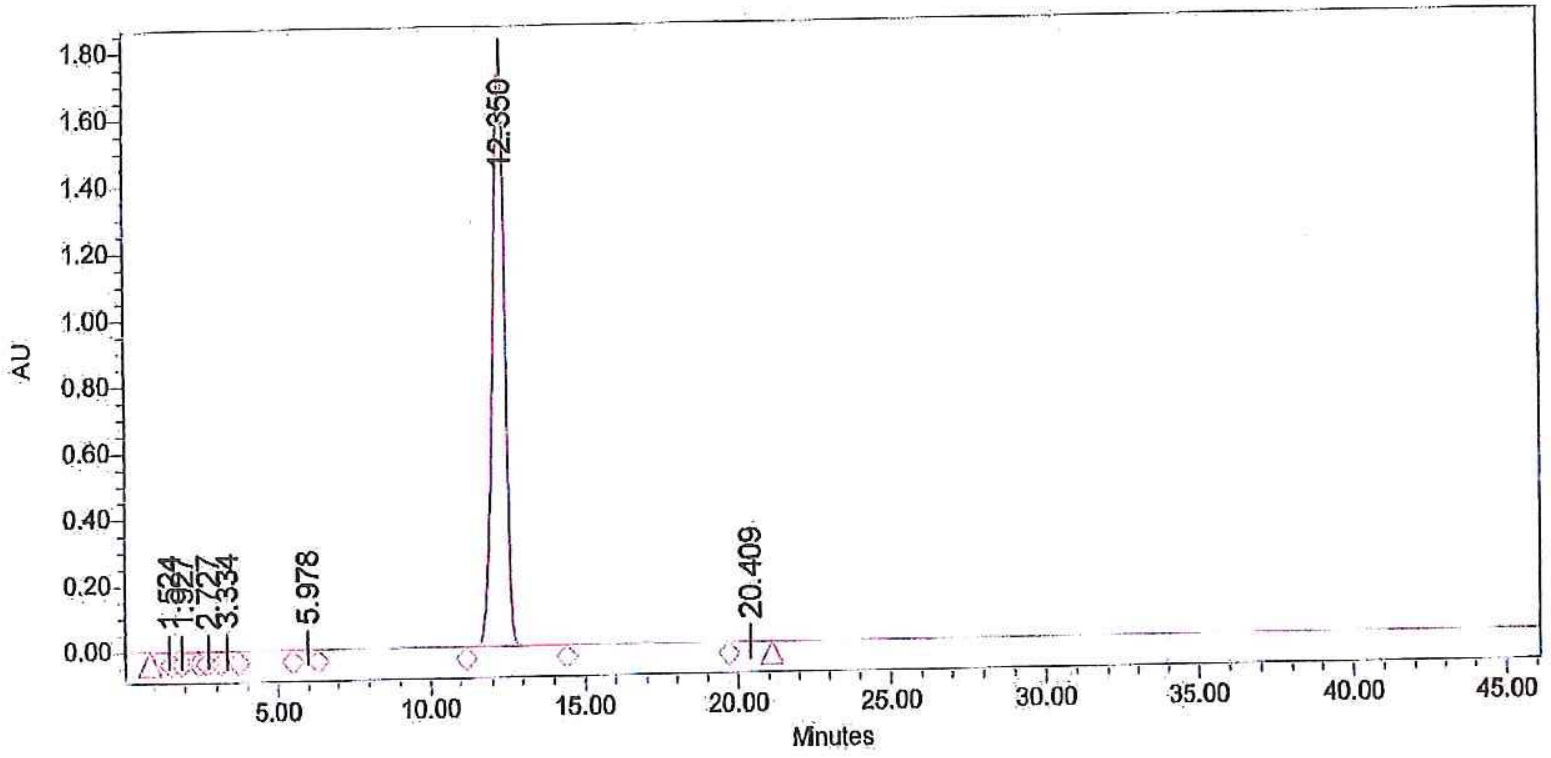

Peak Results

\begin{tabular}{|r|r|r|r|r|r|}
\hline 5 & Name & RT & \multicolumn{1}{|c|}{ Area } & Height & \% Area \\
\hline 1 & & 1.524 & 59638 & 3089 & 0.12 \\
\hline 2 & & 1.927 & 97659 & 3321 & 0.20 \\
\hline 3 & & 2.727 & 53550 & 2279 & 0.11 \\
\hline 4 & & 3.334 & 59006 & 2282 & 0.12 \\
\hline 5 & & 5.978 & 122242 & 6547 & 0.25 \\
\hline 6 & & 12.350 & 48574320 & 1779784 & 99.08 \\
\hline 7 & & 20.409 & 60461 & 1518 & 0.12 \\
\hline
\end{tabular}

Corrypound H 6 
Project Name HPPH

User Name System

Software Version 3.05.01
Report Method Name HPPHrm 2

Current Date

$12 / 11 / 20$

\section{Sample Information}

$\begin{array}{lll}\text { SampleName RR-Prop-But-DP-43-081618 } & \text { Date Acquired } & 8 / 16 / 18 \text { 10:33:41 AM } \\ \text { Column_info C18 symmetry 4.6x150 mm } 5 \mathrm{u} & \begin{array}{l}\text { Acq Method Set } \\ \text { Processing Method 200_800procmeth }\end{array} \\ \text { Injection Volume } \quad 20.00 \mathrm{ul} & \text { Date Processed 8/16/18 11:48:53 AM } \\ \text { Mobile_phase 97/3: } 0.5 \% \text { AcOHMeOH/ } 0.5 \% A c O H & \text { Channel Name 408 nm }\end{array}$

Flow rate $1 \mathrm{ml} / \mathrm{min}$

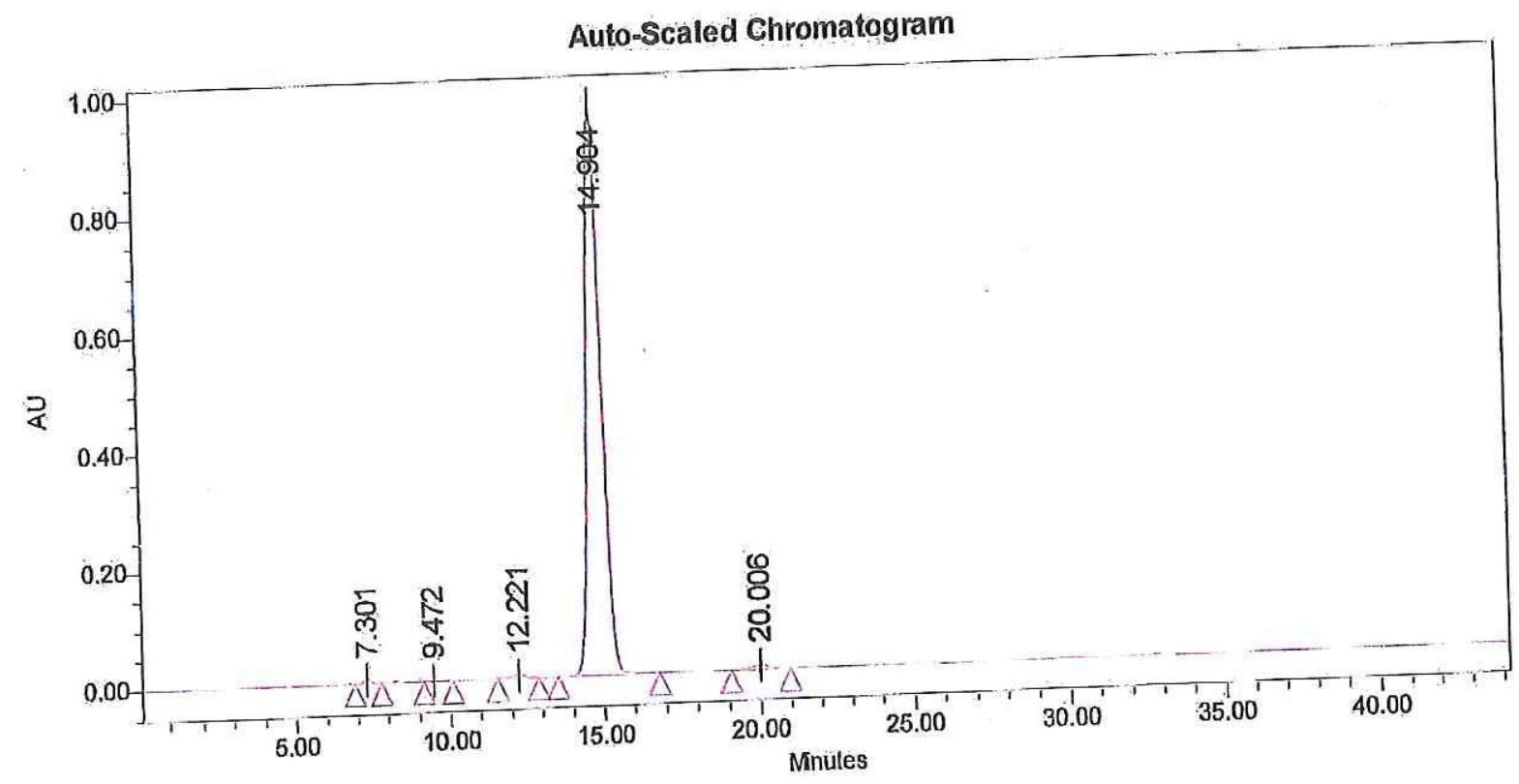

Peak Results

\begin{tabular}{|r|r|r|r|r|r|}
\hline \hline & Name & RT & \multicolumn{1}{c|}{ Area } & Helght & $\%$ Area \\
\hline 1 & & 7.301 & 121917 & 7178 & 0.38 \\
\hline 2 & & 9.472 & 32570 & 1519 & 0.10 \\
\hline 3 & & 12.221 & 172791 & 5570 & 0.54 \\
\hline 4 & & 14.904 & 31600948 & 970047 & 97.96 \\
\hline 5 & & 20.006 & 331626 & 8530 & 1.03 \\
\hline
\end{tabular}

PDA Result Table

\begin{tabular}{|c|c|c|c|c|c|c|c|}
\hline 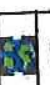 & Name & RT & $\begin{array}{l}\text { Purity1 } \\
\text { Angle }\end{array}$ & $\begin{array}{l}\text { Purity1 } \\
\text { Threshold }\end{array}$ & $\begin{array}{c}\text { Malch1 } \\
\text { Spect. Name }\end{array}$ & $\begin{array}{l}\text { Match1 } \\
\text { Angle }\end{array}$ & $\begin{array}{l}\text { Match1 } \\
\text { Threshold }\end{array}$ \\
\hline 1 & & 7.301 & $2: 758$ & 1.668 & & & \\
\hline
\end{tabular}


Prolect Name HPPH

User Name System

Snfluware Version 3.05.01
Report Method Name HPPHIm 2.

Current Date

\section{Sample Information}

SampleName RR-prop-hex-dp-41-11-08141

Column_info C18 symmetry $4.6 \times 150 \mathrm{~mm} 5 \mathrm{u}$

Injection Volume $\quad 20.00$ ul

Mobile phase $97 / 3: 0.5 \% \mathrm{AcOHMeOH} / 0.5 \% \mathrm{AcO}$
Date Acquired $\quad$ 8/14/18 1:41:01 PM

Acq Method Set HPPH_.

Processing Method 200_800procmeth

Date Processed 8/16/18 3:18:23 PM

Channel Name $408 \mathrm{~nm}$

Flow rate $1 \mathrm{ml} / \mathrm{min}$

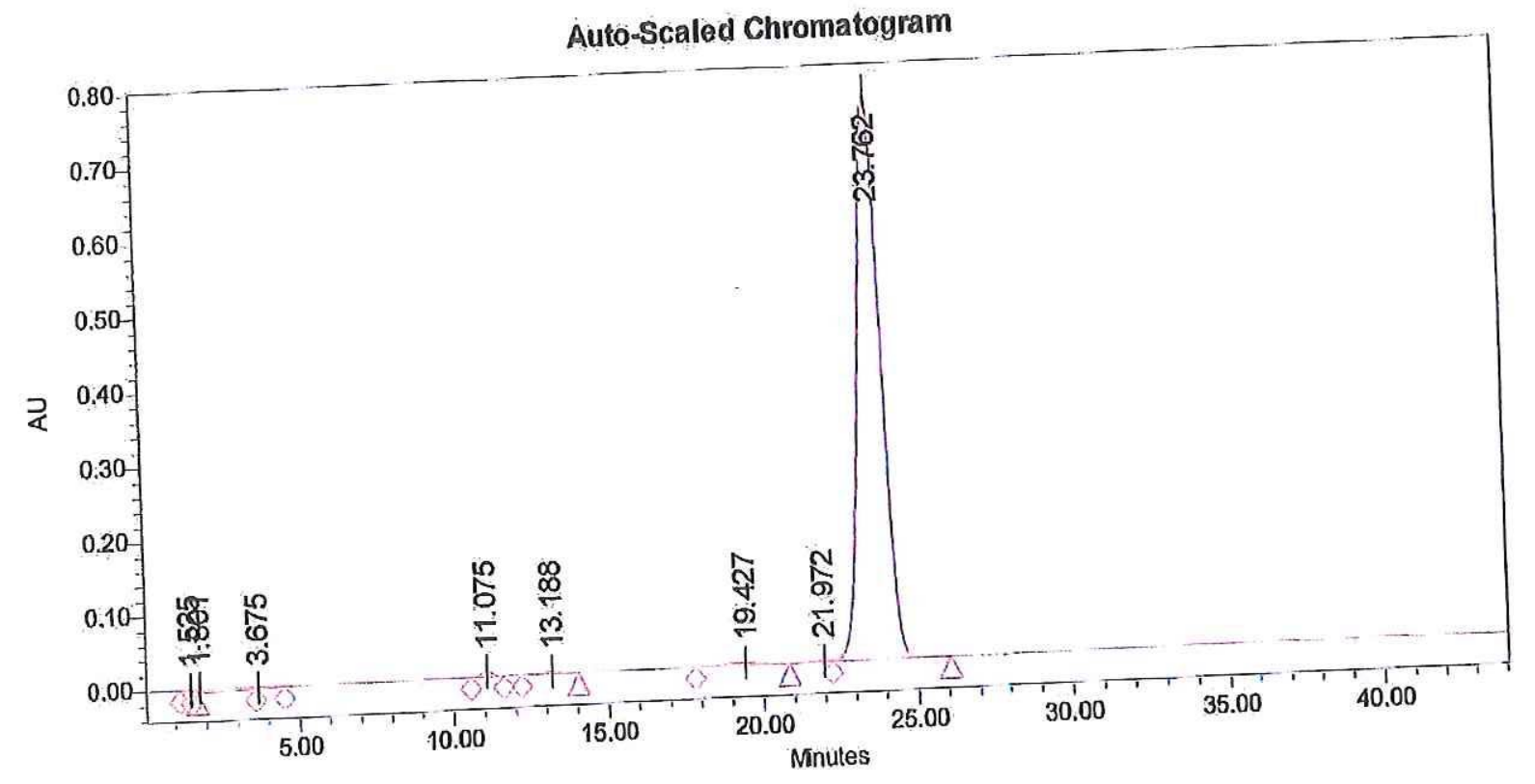

\begin{tabular}{|r|r|r|r|r|r|}
\hline \multicolumn{5}{|c|}{ Peak Results } \\
\hline 1 & Name & RT & \multicolumn{1}{c|}{ Area } & Height & $\%$ Area \\
\hline 1 & & 1.525 & 51347 & 3264 & 0.13 \\
\hline 2 & & 1.801 & 341738 & 6548 & 0.84 \\
\hline 3 & & 3.675 & 97515 & 2086 & 0.24 \\
\hline 4 & & 11.075 & 206918 & 8409 & 0.51 \\
\hline 5 & & 13.188 & 154821 & 3870 & 0.38 \\
\hline 6 & & 19.427 & 308494 & 4076 & 0.76 \\
\hline 7 & & 21.972 & 107026 & 2640 & 0.26 \\
\hline 8 & & 23.762 & 39508761 & 763998 & 96.89 \\
\hline
\end{tabular}


Project Name HPPH

User Namè System

Software Version 3.05.01
Report Method Name HPPHrm_2

Current Date

$12 / 11 / 20$

\section{Sample Information}

SampleName RR-3-Butyl-DP-081518

Column_info C18 symmetry $4.6 \times 150 \mathrm{~mm} 5 \mathrm{u}$

Injection Volume $20.00 \mathrm{ul}$

Mobile_phase $97 / 3$ : $0.5 \%$ AcOHMeOH $1 / 0.5 \% \mathrm{AcOl}$

Flow rate $1 \mathrm{ml} / \mathrm{min}$
Date Acquired $\quad$ 8/15/18 12:44:36 PM

Acq Method Set HPPH

Processing Method 200_800procmeth

Date Processed 12/11/20 1:43:54 PM

Channel Name $408 \mathrm{~nm}$

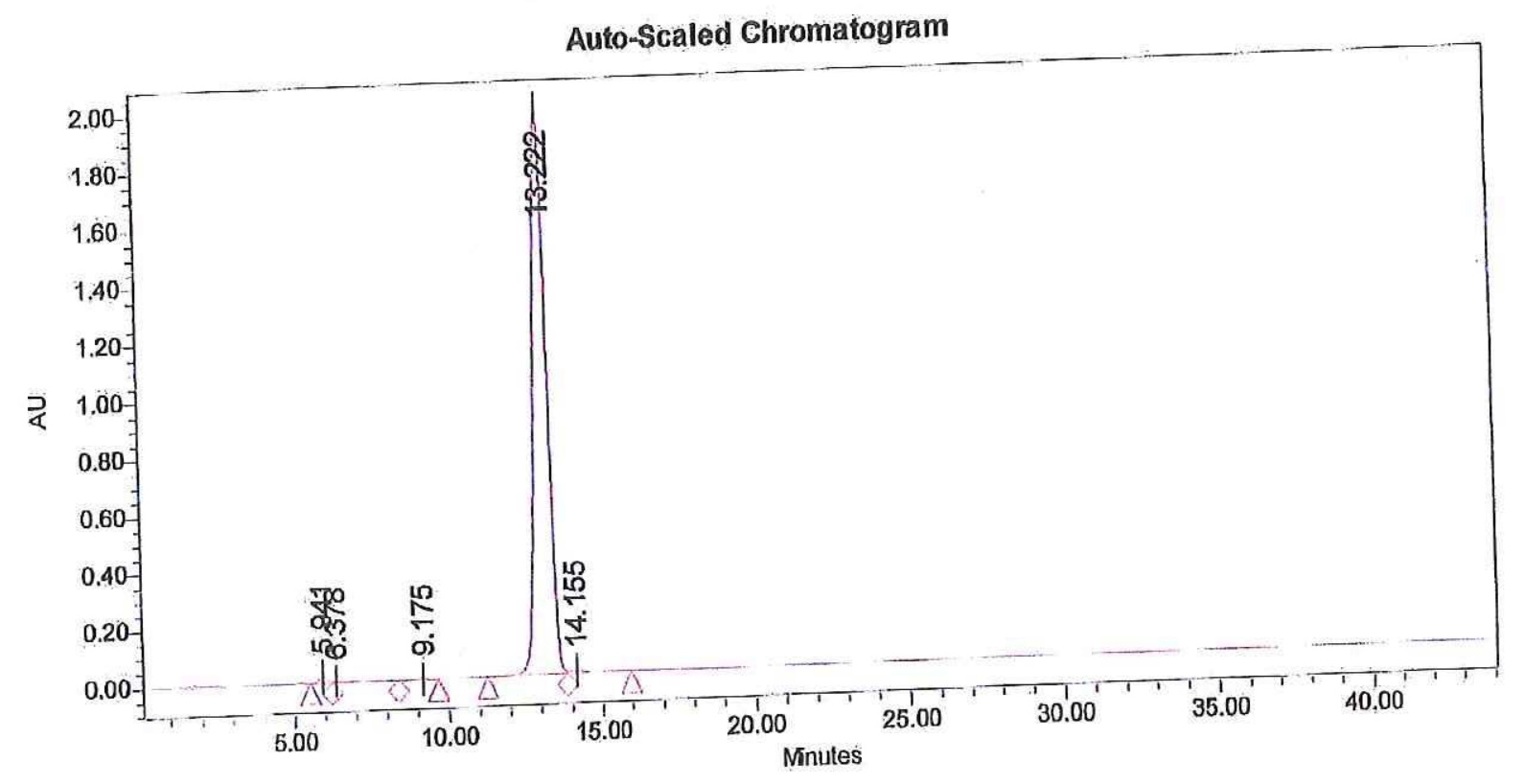

Peak Results

\begin{tabular}{|r|r|r|r|r|r|}
\hline & Name & RT & \multicolumn{1}{c|}{ Area } & Height & $\%$ Area \\
\hline 1 & & 5.941 & 362139 & 21212 & 0.61 \\
\hline 2 & & 6.378 & 113814 & 2631 & 0.19 \\
\hline 3 & & 9.175 & 53201 & 2318 & 0.09 \\
\hline 4 & & 13.222 & 58732254 & 1983671 & 98.60 \\
\hline 5 & & 14.155 & 306336 & 9637 & 0.51 \\
\hline
\end{tabular}

PDA Result Table

\begin{tabular}{|c|c|c|c|c|c|c|c|}
\hline 98 & Name & RT & $\begin{array}{l}\text { Puirily1 } \\
\text { Angle }\end{array}$ & $\begin{array}{c}\text { Purity1 } \\
\text { Threshold }\end{array}$ & $\begin{array}{c}\text { Match1 } \\
\text { Spect. Name }\end{array}$ & $\begin{array}{l}\text { Match1 } \\
\text { Angle }\end{array}$ & $\begin{array}{l}\text { Malch1 } \\
\text { Threshold }\end{array}$ \\
\hline 1 & & 5.941 & 0.736 & 0.599 & & & \\
\hline
\end{tabular}

